\title{
ISSI 2020: Mechanism and Method of Testing Fracture Toughness and Impact Absorbed Energy By Spherical Indentation Tests
}

Jianxun Li

Shandong University

Tairui Zhang

Shandong University

Shang Wang

Shandong University

Jirui Cheng

Shandong University

Weiqiang Wang ( $\nabla$ sduefascf@163.com )

Shandong University

Original Article

Keywords: Spherical indentation tests, Fracture toughness, CIE model, Impact absorbed energy

Posted Date: January 29th, 2021

DOI: https://doi.org/10.21203/rs.3.rs-155417/v1

License: (c) (i) This work is licensed under a Creative Commons Attribution 4.0 International License. Read Full License 


\section{Title page}

\section{Mechanism and Method of Testing Fracture Toughness and Impact Absorbed Energy by Spherical Indentation Tests}

Jian-Xun Li, born in 1993, is currently a PhD candidate at school of mechanical engineering, Shandong University, China. He received his graduate degree from Chinese University of Petroleum, China, in 2019. His research interests include nondestructive testing and ultrahigh cycle fatigue.

Tel: +86-18306483260; E-mail: 963577095@qq.com

Tai-Rui Zhang, born in 1991, received his PhD at the School of Mechanical Engineering, Shandong University, China, 2018. His research interest includes materials testing and mechanics.

E-mail: 1295408193@qq.com

Shang-Wang, born in 1994, received his master degree at the School of Mechanical Engineering, Shandong University, China, 2018. Her main research areas include engineering failure analysis and the determination of fracture toughness through instrumented E-mail: wangshang_sdu@163.com

Ji-rui Cheng, born in 1994, received his master degree at School of Mechanical Engineering, Shandong University, China, in 2019.

E-mail: jerry.chengjirui@foxmail.com

Wei-Qiang Wang, born 1959, received his PhD at the School of Mechanical and Power Engineering, East China University of Science and Technology, Shanghai, China in 1990. Currently, he is Professor at the School of Mechanical Engineering Shandong University, Jinan, China. His research includes engineering failure analysis, supercritical fluid technology and materials testing Tel: +86-0531-8839-5100; E-mail: sduefascf@163.com
Corresponding author:
Tai-Rui Zhang
E-mail:1295408193@qq.com
Wei-Qiang Wang E-mail: sduefascf@163.com 


\title{
Mechanism and Method of Testing Fracture Toughness and Impact Absorbed Energy by Spherical Indentation Tests
}

\author{
Jian-Xun Li ${ }^{1}$ Tai-Rui Zhang ${ }^{1 *} \cdot$ Shang-Wang$^{1} \cdot$ Ji-Rui Cheng ${ }^{1} \cdot$ Wei-Qiang Wang ${ }^{1,2}$ * \\ ${ }^{1}$ Engineering and Technology Research Center for Special Equipment Safety of Shandong Province, Key Laboratory of High-efficiency \\ and Clean Mechanical Manufacture (Ministry of Education), National Demonstration Center for Experimental Mechanical Engineering \\ Education (Shandong University), School of Mechanical Engineering, Shandong University, 17923 Jing Shi Road, Jinan 250061, China \\ ${ }^{2}$ College of Electromechanical Engineering, Qingdao University of Science and Technology, Qingdao, 266061, China \\ * Corresponding author: \\ (1) Tel: +86-186-6891-5630 E-mail address: 1295408193@qq.com (Tai-Rui Zhang) \\ (2) Tel/fax: +86-0531-8839-5100,E-mail address: sduefascf@163.com (Wei-Qiang Wang)
}

\begin{abstract}
Aimed at the problem that conventional approaches for mechanical property determination all need destructive sampling, which may be improper for in-service structures, the authors proposed a method to determine the quasi-static fracture toughness and impact absorbed energy from spherical indentation tests (SITs) in this study. The stress status and damage mechanism of SIT, Mode I fracture, Charpy impact tests, and related tests were first investigated through finite element (FE) calculations and scanning electron microscope (SEM) observations, respectively. It was found that the damage mechanism of SITs is different from Mode I fracture, while the Mode I fracture and Charpy impact test share the same damage mechanism. Taking the difference between SIT and Mode I fracture into consideration, the uniaxial tension and pure shear were introduced to correlate SIT with Mode I fracture. Based on which, the widely used critical indentation energy (CIE) model in fracture toughness determination from SITs was modified. The quasi-static fracture toughness determined from the modified CIE model was used in evaluating the impact absorbed energy by means of the dynamic fracture toughness and energy to crack initiation. Effectiveness of the new proposed method was verified through experiments on four kinds of steels, i.e. Q345R, SA508-3, 18MnMoNbR, and S30408.
\end{abstract}

Keywords: Spherical indentation tests, Fracture toughness, CIE model, Impact absorbed energy

\section{Introduction}

Fracture toughness and impact absorbed energy are two important mechanical parameters reflecting the material's resistance to fracture. Accurate measurement of the two parameters is of great significance for evaluating the structural integrity of materials and ensuring the safety of equipment in long-term service. Conventional fracture and Charpy impact tests all need destructive sampling, and thus cannot be used on in-service structures.

By contrast, the spherical indentation tests (SITs), due to its non-destructive and easy to perform nature, has been extensively investigated as a promising alternate of the conventional destructive tests [1-5].

The method to estimate the quasi-static fracture toughness of materials from a SIT was first proposed by Byun et.al [6], in which the work done by average contact pressure in the direction of impress was defined as Indentation Energy to Fracture $W_{\mathrm{IEF}}$. Then, the fracture toughness $K_{\mathrm{IC}}$ in $\mathrm{N} / \mathrm{mm}^{3 / 2}$ of sample material can be determined with an application of the Griffith theory [7].

$$
W_{\mathrm{IEF}}=\frac{1}{\pi a^{2}} \int_{0}^{h_{C}} P \mathrm{~d} h
$$

where $h$ and $h_{\mathrm{c}}$ in mm are the indentation depth and critical indentation depth, respectively, $P$ in $\mathrm{N}$ is the external load, and $a$ in $\mathrm{mm}$ is the contact radius.

$$
K_{\text {IC }}=\sqrt{2 E W_{F}}
$$

where $E$ in $\mathrm{MPa}$ is the Young's modulus of the specimen material. $W_{\mathrm{F}}$ in $\mathrm{kJ} / \mathrm{m}^{2}$ is the energy required to form a unit area crack and can be approximated as $W_{\mathrm{IEF}}$ in $\mathrm{kJ} / \mathrm{m}^{2}$.

To overcome the drawback of Byun's method, which asks for an additional destructive tensile test, Haggag [8] empirically concluded the judgement for critical indentation depth by taking the difference between brittle fracture and ductile fracture into consideration (named as Haggag toughness method, HTM). Meanwhile, the calculation formula of fracture toughness was modified by considering the lower platform of fracture toughness at low temperature, 
as shown in Eq. (3).

$$
K_{\mathrm{IC}}=30+\sqrt{2 E W_{F}}
$$

The HTM is applicable for a wide range of temperatures and does not need any additional destructive test. However, the judgement for critical indentation depth was empirically concluded, and its effectiveness largely depends on specimen materials [9]. Additionally, the HTM does not provide any explanation on the mechanism in obtaining fracture toughness from SITs.

The mechanism of fracture toughness calculation from SITs was investigated through the continuum damage mechanics (CDM) Lee [10], who developed the critical indentation energy (CIE) model by finite element (FE) analysis and microscopic observation. The critical indentation energy is calculated as follows.

$$
2 W_{\mathrm{F}}=\frac{1}{\pi a^{2}} \int_{0}^{h_{\mathrm{C}}} P \mathrm{~d} h
$$

where $2 W_{\mathrm{F}}$ is the energy required to form two crack surfaces.

According to the Griffith theory, the fracture toughness $K_{\text {IC }}$ can be calculated with Eq. (4) and Eq. (2).

$$
K_{I \mathrm{C}}=\sqrt{\frac{E P}{\pi} \ln \left(\frac{2 R}{2 R-h_{\mathrm{C}}}\right)}
$$

where $R$ in $\mathrm{mm}$ is the radius of the indenter.

The CIE model, which introduced the CDM to obtain the critical indentation depth, has been widely applied in previous researches [11-13]. However, the critical damage variable $D^{*}$ used in the previous CIE model was determined from the analysis of a moving crack-tip, in which the specimen was considered an elastic perfectly plastic material (i.e. the hardening behavior was neglected) [14]. Additionally, the difference between the damage at high stress triaxiality and the low stress triaxiality was also neglected [15].

Unlike numerous fracture toughness calculation models, there are few reports on evaluating the impact absorbed energy from SITs. Most of the current studies still focus on correlating the impact absorbed energy to the quasi-static and dynamic fracture toughness [16]. Barsom et al. [17] carried out a large amount of impact tests and conventional fracture tests, and proposed the empirical formulas for impact absorbed energy $\left(K V_{2}\right)$, static fracture toughness $\left(K_{\mathrm{IC}}\right)$ and dynamic fracture toughness $\left(K_{\mathrm{ID}}\right)$. When $J$-integral theory was proposed, P. Hübner [18] established the relationship between fracture toughness and impact absorbed energy ( $J$ and $K V_{2}$ ) from the perspective of energy. Combined with experimental and numerical approaches,
Smith [19] contrasted the fracture behavior of pre-cracked fracture specimens tested quasi-statically with Charpy Vnotch specimens tested both quasi-statically and dynamically, and proposed energy scaling model for relating impact absorbed energy to fracture toughness which is suitable for both static and dynamic loading. Obtaining impact absorbed energy from empirical model is simple in calculation and stable in results, but the determination of empirical model often requires a large amount of destructive tests for fracture toughness which are more complex than impact tests in process.

To summarize, it can be seen from the above research that there are two or three methods to obtain the fracture toughness of materials by SITs, but the calculation accuracy of these models need to be improved [20]. The study of fracture toughness and impact absorbed energy is relatively common. However, most of the testing methods need destructive sampling, which may not be suitable for inservice structures.

Authors in this study focus on proposing a method to determine the quasi-static fracture toughness and impact absorbed energy from SITs. The main technical route in this paper is shown in Fig.1. The mechanism analysis for specimens under the SITs, Mode I fracture tests and Charpy impact tests were carried out with the micro-observation and finite element (FE) calculations. The similarity of these damage mechanisms was discussed by the comparison. Then, depending on existing theory $[21,22]$ for mechanisms correlation, the correlation analysis of the three damage mechanisms was conducted. Based on the correlation analysis for the quasi-static fracture toughness, dynamic fracture toughness and crack initiation energy, the calculation methods for fracture toughness and impact absorbed energy by SITs were proposed. Finally, reliability of the proposed method was verified through experiments on four kinds of steels.

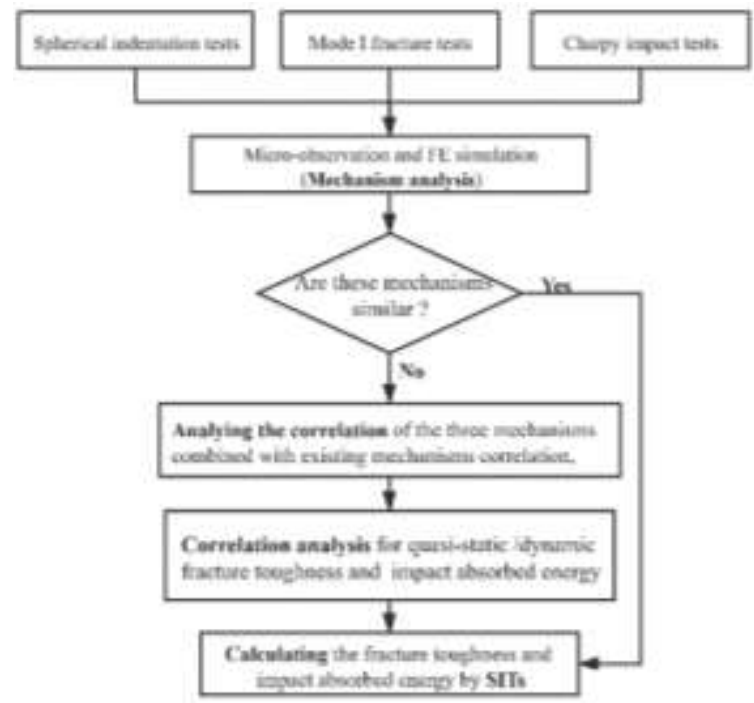

Figure 1 The main technical route 


\section{Experiments}

\subsection{Materials}

Four kinds of steels, Q345R, SA508-3, 18MnMoNbR, and S30408, were used in quasi-static tensile tests, dynamic tensile test, mode I fracture tests, SITs, and Charpy impact tests. The chemical composition of each material tested by Bruker Tasman Q4 spectrograph is provided in Table 1 with the corresponding standards.

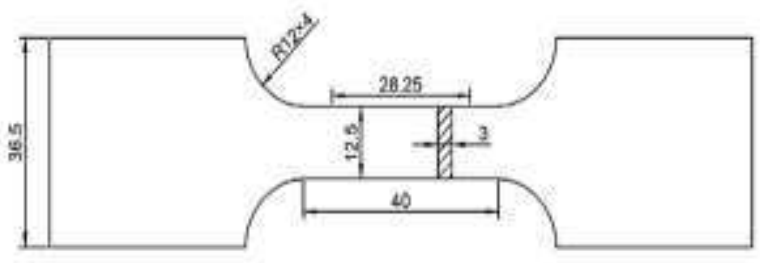

Figure 3 Configuration of the dynamic tensile specimen

Table 1 Chemical composition of the material and corresponding standard values

\begin{tabular}{|c|c|c|c|c|c|c|c|}
\hline Material & $\mathrm{C}$ & $\mathrm{Si}$ & $\mathrm{Mn}$ & $\mathrm{Cr}$ & Mo & $\mathrm{Ni}$ & $\mathrm{Nb}$ \\
\hline Q345R & 0.160 & 0.255 & 1.412 & 0.014 & $<0.001$ & 0.0061 & - \\
\hline GB713-2014 [23] & $\leq 0.20$ & $\leq 0.55$ & $1.20 \sim 1.60$ & $\leq 0.30$ & $\leq 0.08$ & $\leq 0.30$ & - \\
\hline SA508-3 & 0.226 & 0.194 & 1.475 & 0.956 & 0.469 & 0.227 & - \\
\hline ASME code [24] & $\leq 0.25$ & $0.15 \sim 0.40$ & $1.20 \sim 1.50$ & $0.40 \sim 1.00$ & $0.45 \sim 0.60$ & $\leq 0.25$ & - \\
\hline 18MnMoNbR & 0.140 & 0.264 & 1.315 & 0.166 & 0.524 & 0.160 & 0.036 \\
\hline GB713-2014 [23] & $\leq 0.21$ & $0.15 \sim 0.50$ & $1.20 \sim 1.60$ & $\leq 0.30$ & $0.45 \sim 0.55$ & $\leq 0.30$ & $0.025 \sim 0.05$ \\
\hline S30408 & 0.048 & 0.479 & 1.170 & 18.33 & 0.049 & 8.248 & 0.0059 \\
\hline GB12771-2019 [25] & $<0.08$ & $\leq 0.75$ & $\leq 2.00$ & $18.00 \sim 20$. & - & $8.00 \sim 11$ & - \\
\hline
\end{tabular}

\subsection{Quasi-static tensile test}

The quasi-static tensile specimens were machined into rod-shaped ones with a diameter of $10 \mathrm{~mm}$, gauge length of $50 \mathrm{~mm}$, and total length of $194 \mathrm{~mm}$ according to Chinese standard [26]. The specific geometries of tensile specimen are shown in Figure 2. The tensile tests were performed on AG-IC universal testing machine at a loading speed of $1 \mathrm{~mm} / \mathrm{min}$ until it broke, and the displacement was measured by an extensometer.

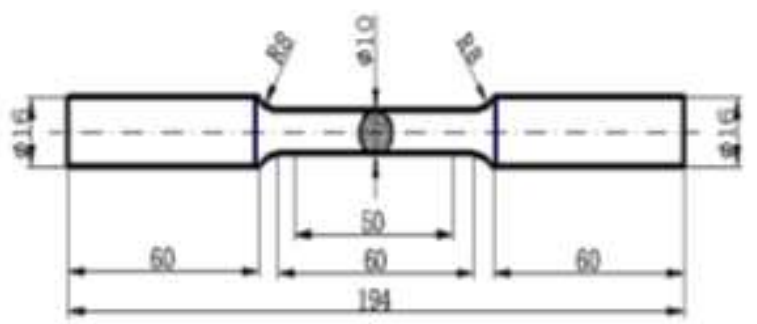

Figure 2 Configuration of the quasi-static tensile specimen.

\subsection{Dynamic tensile test}

The dynamic tensile specimens were machined into plate specimens with thickness of $3 \mathrm{~mm}$, gauge length $40 \mathrm{~mm}$, and width of $12.5 \mathrm{~mm}$ in accordance with the Chinese standard [26]. The detailed configuration of dynamic tensile specimen was shown in Figure 3. In accordance with the strain rate of Charpy impact test $\left(10 \mathrm{~s}^{-1}\right)$, strain controlled (set tensile speed at $0.4 \mathrm{~m} / \mathrm{s}$ ) tests were conducted on HTM5020 .
For the high strain rate tests, the strain of the specimen was determined by digital image correlation (DIC) instead of common extensometer measurement. Before the tests, the speckles were sprayed on the gauge section of the specimens, and the speckle quality was statically calibrated. The speckle patterns under tensile tests were captured by super high speed digital camera (APX-RS) with speed of $10^{6} \mathrm{~s}^{-1}$. Then, the plastic strain distribution on the specimen surface was obtained by the commercial DIC system VIC-2D 6 (Correlated Solutions) with the captured pictures. A typical specimen speckle photograph is shown in Figure 4.

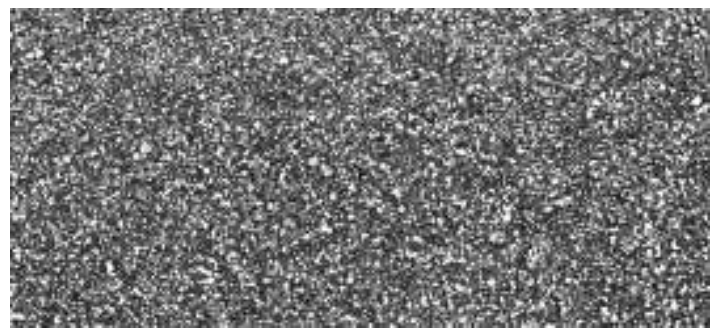

Figure 4 Typical specimen speckle photograph

\subsection{Spherical indentation tests}

The specimens were cut into blocks with $10 \times 10 \times 50 \mathrm{~mm}^{3}$. and polished to smooth surface. The SITs were carried out on the Stress-Strain Microprobe system B4000, as shown in Figure 5, using a tungsten carbide indenter with a diameter of $0.76 \mathrm{~mm}$ (the Young's modulus and Poisson's ratio of indenter are $710 \mathrm{GPa}$ and 0.23 , respectively). To ensure the quasi-static characteristics of the test, the loading and unloading rate was set at $0.1 \mathrm{~mm} / \mathrm{min}$. The load-depth curve 
obtained from the 8-cycle spherical indentation test is shown in Figure 6, in which the maximum indentation depth $h_{\max }$ was set at $0.24 \mathrm{R}$.

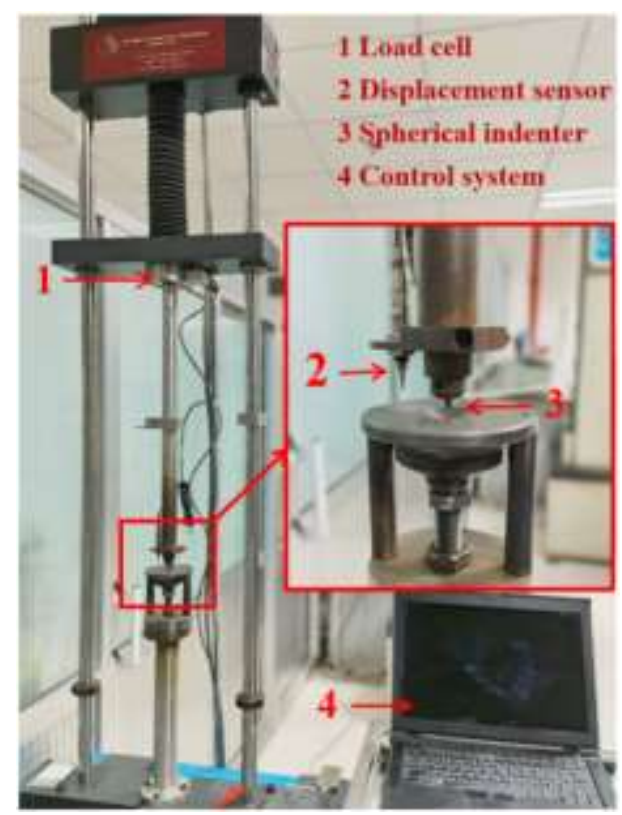

Figure5 Stress-Strain Microprobe system B4000

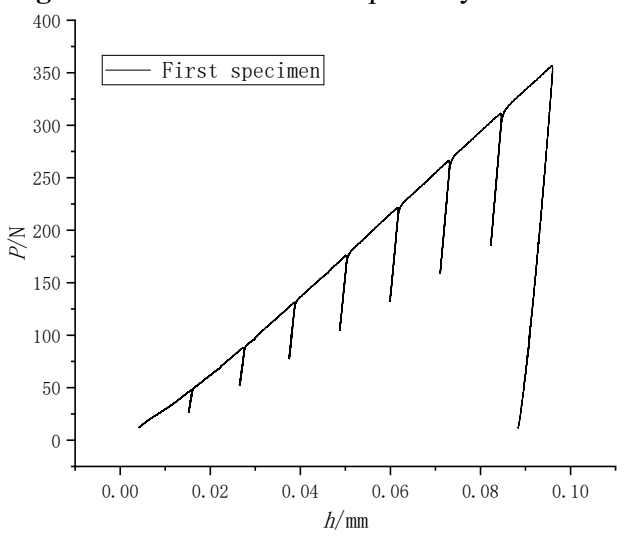

Figure 6 Load-depth curve of from SITs

\subsection{Mode I fracture tests}

A standard compact tensile (CT) specimen with a thickness of 0.45 inch and a ratio of nominal width to nominal thickness of 2 was used, as shown in figure 7 . The pre-cracking was performed on a high-frequency fatigue testing machine with the stress ratio and frequency set at 0.1 and $100 \mathrm{~Hz}$, respectively. The length of fatigue crack on the surface was recorded every 20000 cycles during precracking, while reversed the specimen to ensure that the crack length on both sides of the specimen is basically the same. Aimed to strengthen the plane strain state of the fatigue crack tip, a side groove with a depth of $1.5 \mathrm{~mm}$ and an angle of $90^{\circ}$ was machined on the surface of the specimen after pre-cracking. The CT tests were also performed on
Stress-Strain Microprobe (SSM) system B4000.

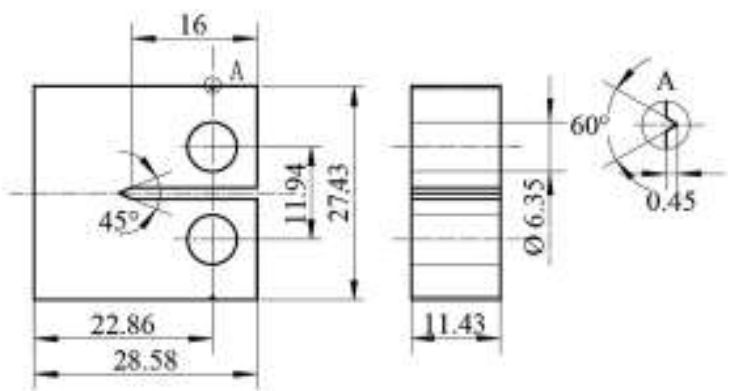

Figure 7 Configuration of the CT specimen

For ductile metals, the preformed cracks propagate the slowly and steadily, and thus the plane strain fracture toughness $K_{\text {IC }}$ cannot be ascertained directly. According to the relevant standard [27], unloading compliance method with a single specimen can be used to determine the crack initiation resistance curve of ductile materials, i.e. $J-R$ resistance curve. The intersection point of the structural line with $0.2 \mathrm{~mm}$ offset and the $J-R$ curve was used as engineering fracture toughness, i.e. $J_{\mathrm{IC}}$ in $\mathrm{kJ} / \mathrm{m}^{2}$. Then, $K_{\mathrm{IC}}$ was calculated by

$$
K_{I C}=\sqrt{\frac{E}{1-v^{2}} J_{I C}}
$$

\subsection{Charpy impact tests}

The Charpy impact test is conducted to obtain the crack initiation energy and the impact absorbed energy. The test was performed on the RKP450 impact testing machine with 450J hammer in accordance with the requirements of Chinese standard [28]. Aimed to observe the process of crack initiating and extending visually, the test is carried out on a self-designed tooling which will stop the hammer after the crack initiation to protect the sample from fracture. To ensure the effectiveness of the test, the crack arrest test was carried out at $1.7 \mathrm{~mm}, 1.8 \mathrm{~mm}$ and $1.9 \mathrm{~mm}$ away from the end face of the sample by changing the cushion block. The configuration of the Charpy impact test specimen and the tooling for crack arrest were shown in Figure 8 and Figure 9 , respectively.
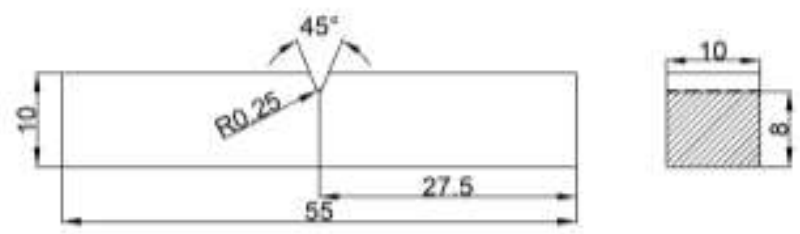

Figure 8 Configuration of the Charpy impact test specimen 

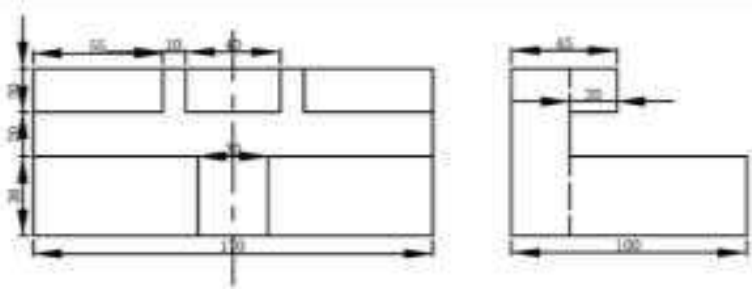

Figure 9 Configuration of the crack arrest tooling

\section{FE simulation}

Considering the damage of ductile materials is closely related with the stress state, the SIT, Mode I fracture and Charpy impact tests were first numerically investigated through ABAQUS 6.14.

\subsection{FE model of mode I fracture tests}

Taking the characteristics of the CT specimen (Mode I fracture) into consideration, the FE model was developed.

In this calculation, the contact pair between the pin and specimen was regarded as surface-to-surface contact, with the friction coefficient set at 0.2 [29]. In order to ensure the calculation accuracy and save the cost, 4-node bilinear axisymmetric elements in incompatible modes (CAX4I) was adopted. Meshes around the pre-cracked region (set as $2 \mathrm{~mm} \times 2 \mathrm{~mm}$ ) were gradually refined to $0.05 \mathrm{~mm}$, while those in the distal region were set at $0.04 \mathrm{~mm}$, as shown in Figure 10. As the same in the fracture toughness test, the pin on the left of the model was fixed, and the pin on the other side was displacement controlled with the maximum displacement of $2 \mathrm{~mm}$.
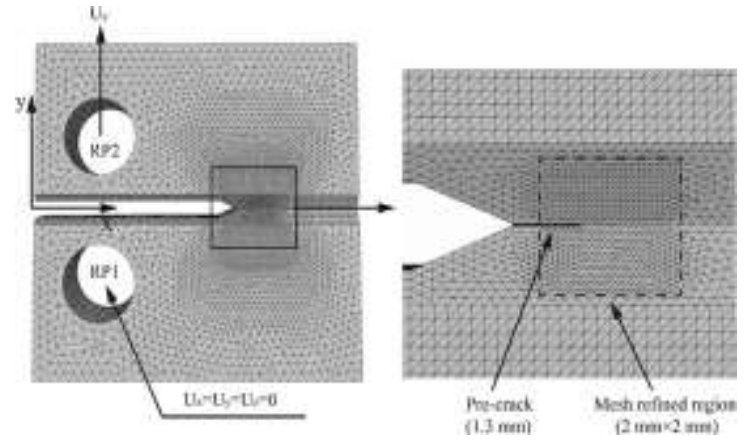

Figure 10 Illustration of the FE model of Mode I fracture tests

A comparison of the load $P$-displacement $q$ curve from Mode I fracture tests and numerical simulations with different mesh density (verified the mesh independence) is provided in Figure 11.

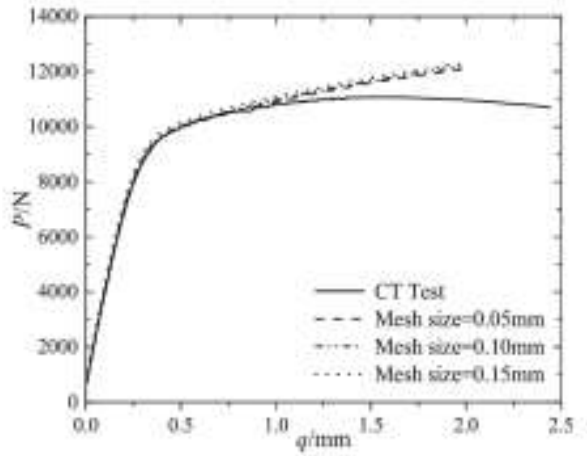

Figure 11 Comparison of the $P-q$ curves from tests and FEA

\subsection{FE model of Charpy impact tests}

Taking the characteristics of the Charpy impact specimen into consideration, a quarter model, as shown in Figure 12, was created to determine the stress distribution and the variation of stress triaxiality $\sigma_{\text {Tri }}$ at the V-notch tip.

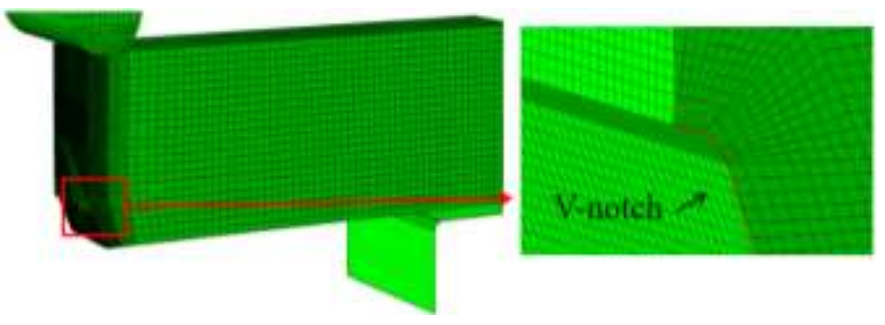

Figure 12 Illustration of the FE modeling of impact test

An 8-node linear brick (C3D8R) was adopted, the meshes around V-notch and hammer tips were refined to $0.1 \mathrm{~mm}$ for calculation accuracy, and the overall mesh sizes for the specimens were $0.5 \mathrm{~mm}$. According to the impact test, the initial velocity of the hammer that limited to the direction of $Y$ axis was set as $5.2 \mathrm{~m} / \mathrm{s}$. Meanwhile, the support was regarded as a rigid body, and its movement was fixed.

\subsection{FE model of SITs}

Considering the characteristic of SITs, an axisymmetric model was established to analyze the stress state, as shown in the Figure 13.

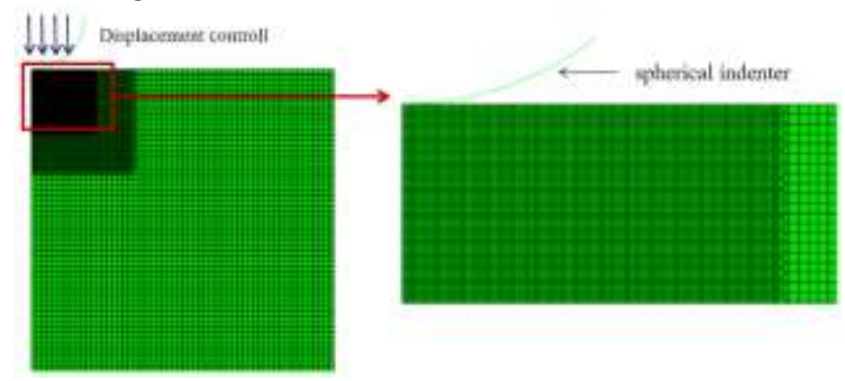

Figure 13 Illustration of the FE modeling of SITs 
The indenter was considered a rigid body whose diameter was the same as experiment used one, while the element type of specimen was set as a 4-node bilinear axisymmetric quadrilateral (CAX4R). The contact setting of SITs is similar to that in the FE model of Mode I fracture test, where the indenter and specimen surfaces were defined as the master and slave surfaces, respectively. According to the previous research [21], the minimum mesh size of the region near the indenter was $0.002 \mathrm{~mm}$, and the maximum mesh size of the edge region was $0.018 \mathrm{~mm}$. The FE calculation of SIT was displacement control, and the maximum depth was set in accordance with SITs (i.e. $h_{\max }=0.24 \mathrm{R}$ ).

\section{Calculation method of fracture toughness based on SITs}

\subsection{Stress state analysis}

\subsubsection{Mode I fracture tests}

The Mises stress distribution of the pre-crack tip along the thickness with the loading line displacement of $q=0.75 \mathrm{~mm}$ on the specimen was shown in Figure 14(a). As the figure shown, the maximum Mises stress appears on center of the specimen, decreased gradually with the increase of distance from center, and the Mises stress distribution is approximately "elliptical", which leads to the growing crack propagates forward in an oval shape. The Mises stress distribution at the front edge of crack tip in the middle section of specimen is shown in Figure 14(b). The result indicated that blunting deformation of the crack tip occurred with the increase of loading line displacement, and the stress distribution surround the crack tip is in the shape of the fins, which is the same as the theoretically determined plane strain plastic zone shape [7]. The Mises stress around the $\mathrm{V}$-notch decreased rapidly along the direction of crack propagation, where the maximum locates at the region $45^{\circ}$ inclined to the vertical direction.

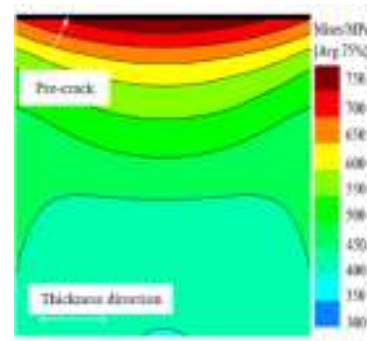

(a) Section in thickness direction

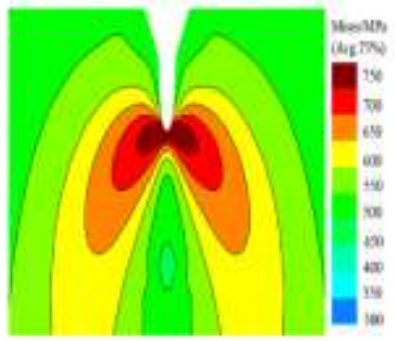

(b) Middle section
Figure 14 Mises stress distribution of CT specimen $(q=0.75 \mathrm{~mm})$

For a better understanding of the stress state of CT specimen, the stress triaxiality $\sigma_{\text {Tri }}$ was determined from the region ahead the pre-crack tip and its development with the loading line displacement $q$ was provided in Figure 15.

The variation of the $\sigma_{\text {Tri }}$ increased with $q$ significantly at the beginning of loading, but it almost approached a constant when loading to $0.75 \mathrm{~mm}$. The slight decrease of $\sigma_{\text {Tri }}$ may be caused by the excessive plastic deformation at the pre-crack tip after $q$ reaches $1.5 \mathrm{~mm}$.

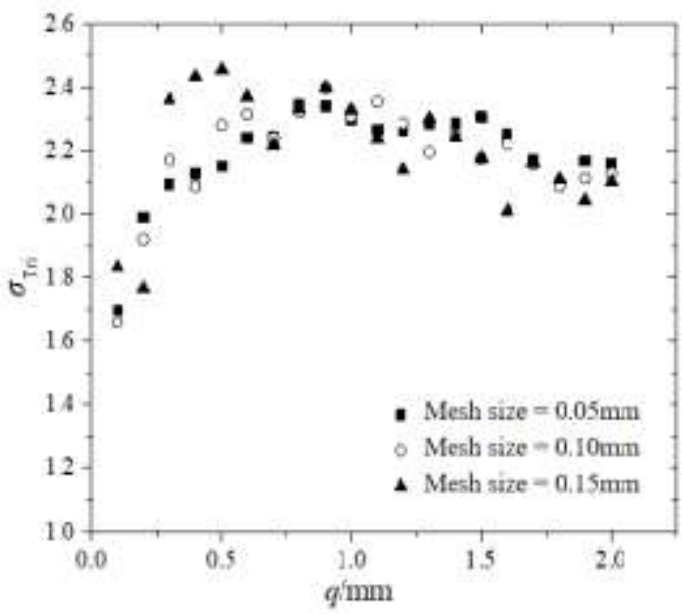

Figure 15 Variation of $\sigma_{\text {Tri with }} q$ at the crack tip under Mode I loading

\subsubsection{Spherical indentation tests}

The Von Mises stress and shear stress distributions $\left(h_{\max }=0.24 R\right)$ around the indentation area are presented in Figure 16 and Figure 17, respectively. The indentation induced plastic flow is approximately spherical. However, due to the existence of friction, the plastic flow at the indentation bottom is suppressed, while that at the 'wing region' (i.e. the region around $45^{\circ}$ inclined to the loading axis). It can be seen that the distribution of shear stress and Mises stress is basically the same, the area of stress concentration were considered as the damage zone in SITs. The $\sigma_{\text {Tri }}$ increases with the increase of indentation depth, which can be confirmed by the curves extracted from the damage area (location of maximum shear stress) presented in Figure 18. It indicated that the damage area always subjected to the compressive stress during the loading process $\left(\sigma_{\text {Tri }}\right.$ varies from -2.18 to -1.87$)$, and the restraint effect of hydrostatic stress on the damage area decreases with the increasing indentation depth. 


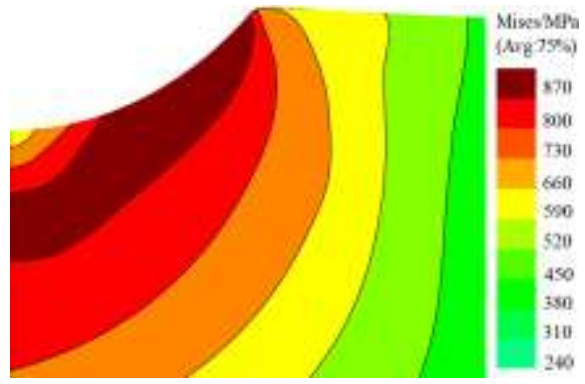

Figure 16 Mises stress distribution around indentation

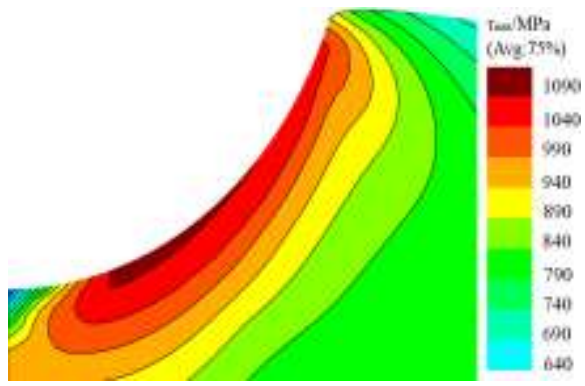

Figure 17 Shear stress distribution around indentation

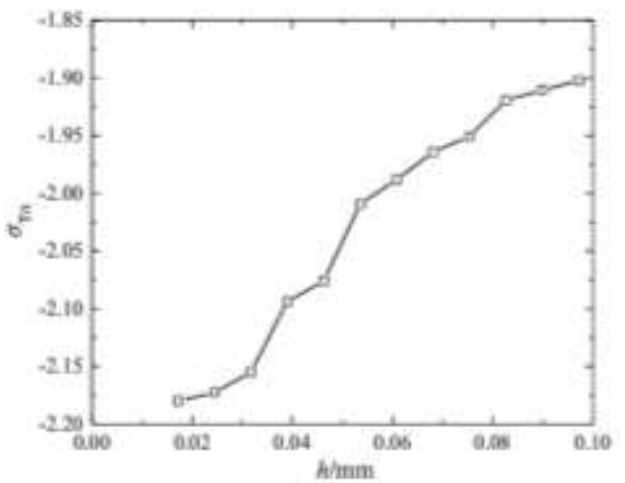

Figure 18 Variation of $\sigma_{\text {tri }}$ with $q$ (the region of maximum shear stress)

\subsection{Damage mechanism analysis}

In order to ensure the consistency, all the microscopic observations were performed on the same material (Q345R).

Micro morphology of the indentation section surface is shown in Figure 19, with lots of wedge-shaped voids around the border of residual indentation, which is similar to the shear damage explained with the dislocation pile-up [30]. It was found that many wedge-shaped voids locate in the 'wing region', while almost no void was observed at the indentation bottom. The damage distribution consists well with the shear stress concentration presented in section 4.1.2. Thus, it can be concluded that the shear stress is the main reason for the initiation and localized distribution of voids in indentation test, and the damage mechanism in SITs is the same as that in pure shear test. As reported in a previous study [21], the Mode I fracture surface exhibits a typical dimple feature, which is similar to the tensile fracture. The micro morphology near crack tip was shown in Figure 20, with lots of spherical or ellipsoidal voids in the region under Mode I loading. Therefore, it shares the same damage mechanism with the uniaxial tensile tests.

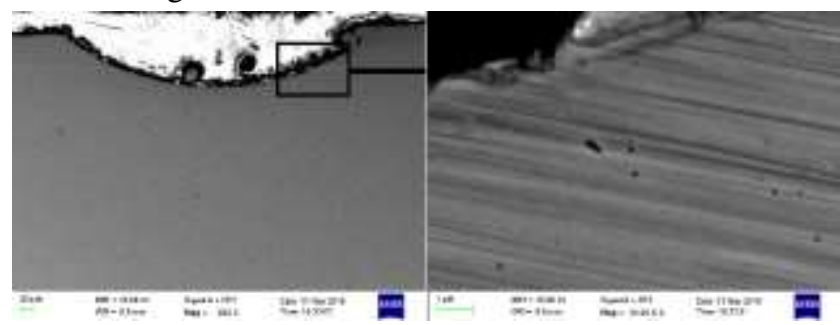

Figure 19 Microstructure of residual indentation

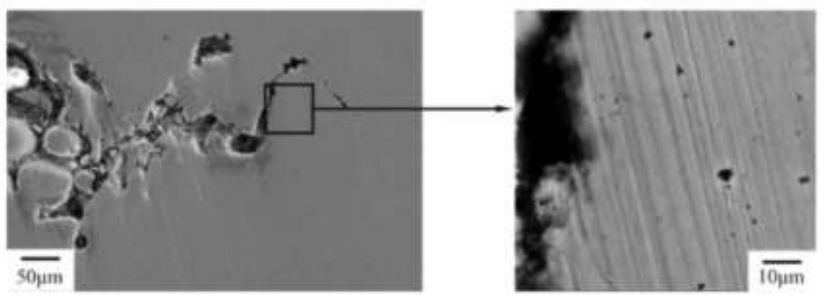

Figure 20 Observation of section surface for Mode I specimen [21]

The mechanisms of tensile fracture and shear fracture are essentially different. However, the initiation and growth of voids and micro-cracks lead to the decrease of effective bearing area, and thus cause a reduction of effective elastic modulus (Young's modulus is used to characterize tensile damage and shear modulus is used to characterize shear damage). According to the micromechanics and the material will fracture when the elastic modulus reaches its critical value. It was proposed by Shi et al. [22] that the critical damage strain energy release rate is a material constant which is independent of the stress state. Therefore, the $D_{\text {II }}$ can be calculated from the $D_{\mathrm{I}}$.

$$
\frac{1-D_{\mathrm{I}}^{*}}{1-D_{\mathrm{II}}^{*}}=\sqrt{\frac{3}{2(1+v)}}
$$

where $D_{\mathrm{I}}{ }^{*}$ is the critical tensile damage variable and $D_{\mathrm{II}}{ }^{*}$ is the critical shear damage variable of the material.

According to the mechanism analysis, the critical damage variable under Mode I fracture test and the SITs corresponds to $D_{\mathrm{I}}{ }^{*}$ and $D_{\mathrm{II}}{ }^{*}$, respectively, which could be used in the Eq. (7).

\subsection{Modified CIE model}

The previous CIE model creatively introduced the CDM into indentation test, but there are some shortcomings in the model as mentioned in section 1. First, the critical damage variable $D^{*}$ used in the previous CIE model was from Andersson's numerical analysis [31], in which the material was assumed elastic perfectly plastic (i.e. the effect of work 
hardening was neglected). Additionally, the $D^{*}$ have not been verified by experiments. Moreover, the difference between the damage mechanism at high stress triaxiality and low stress triaxiality was neglected in the model.

To obtain the critical damage variable of materials, cyclic loading tensile tests are carried out, as mentioned in section 2.2. The true stress-stain curve of SA508-3 is shown in Figure 21. Considering the effect of necking on determination of the stress-strain curve, only the data before obvious necking was used. Besides, only the first $40 \%$ data of unloading curve was used to avoid the effect of back stress relaxation [32]. The tensile damage variable $D_{\text {I }}$ could be characterized by effective Young's modulus in MPa [33].

$$
D_{\mathrm{I}}=1-\frac{E_{\text {eff }}}{E}
$$

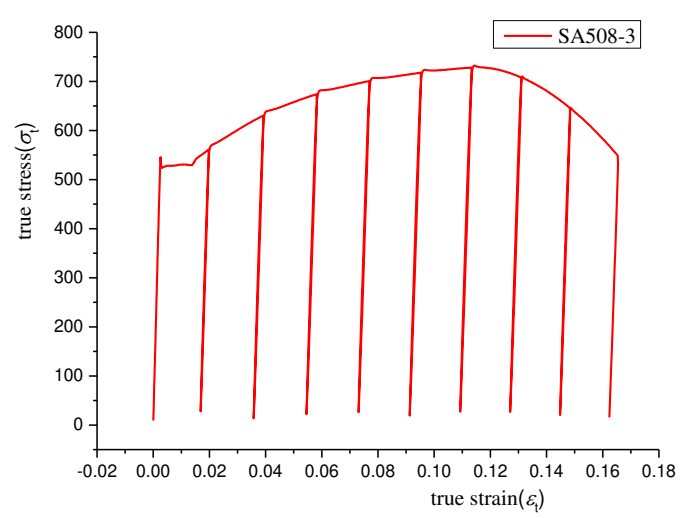

Figure 21 True stress-strain curve from cyclic loading tensile tests (SA508-3)

The variation of $D_{\text {I }}$ with true strain was presented in Figure 22. The damage variable of four materials increases with the increase of true strain at the beginning, and then tends to a constant. As shown in the Figure 22, the value of critical damage variable $D_{\mathrm{I}}{ }^{*}$ ranges from 0.20 to 0.23 , which is consistent with the $D_{\mathrm{I}}{ }^{*}$ (about 0.22 ) measured through tension tests by predecessors [33]. To obtain a more conservative fracture toughness calculation for engineering application, a conservative $D_{\mathrm{I}}{ }^{*}=0.2$ is used for all materials in this study. According to Eq. (7), the critical shear damage variable of all materials $D_{\mathrm{II}}{ }^{*}$ is calculated as 0.25 . Since the damage around the indentation was almost caused by shear stress, the critical indentation depth $h_{\mathrm{c}}$ should be determined by $D_{\text {II }}{ }^{*}$

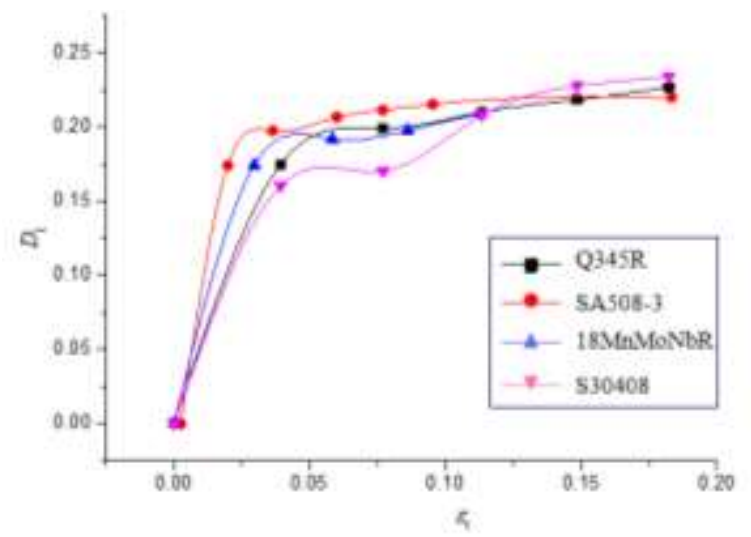

Figure 22 Variation of tensile damage with true strain

As for the determination of $E_{\text {eff }}$ from SITs, the PharrOliver formula was adopt in the previous CIE model [34]. However, it is important to note that the plastic deformation of specimen before unloading was not taken account in the Pharr-Oliver formula, i.e. Eq.(9), which lead to an obvious reduction of effective Young's modulus at a small indentation depth [34, 35].

$$
E_{\mathrm{PO}}=\frac{1-v^{2}}{2 \sqrt{\frac{A_{\mathrm{c}}}{\pi}} / S-\left(1-v_{\text {ind }}^{2}\right) / E_{\text {ind }}}
$$

where $v$ and $v_{\text {ind }}$ are the Poisson's ratio of specimen and the spherical indenter, respectively, $S$ and $E_{\text {ind }}$ are the slope of unload curve and Young's modulus of the spherical indenter, respectively. $A_{\mathrm{c}}$ is the contact area between the indenter and the specimen.

To consider the plastic deformation of the material during SITs, the modified effective Young's modulus formula was proposed in our previous study [29], as follows

$$
E_{\text {eff }}=\frac{1-v^{2}}{2 \sqrt{\frac{h_{\mathrm{r}} R R_{0}}{R_{0}-R}} / S-\left(1-v_{\text {ind }}^{2}\right) / E_{\text {ind }}}
$$

$R_{0}$ and $h_{\mathrm{r}}$ in mm are the radius of residual indentation and secondary loading depth, obtained by the Eq. (11) and (12), respectively.

$$
\begin{gathered}
R_{0}=\frac{h_{\mathrm{p}}^{2}+\left(2 h_{\text {max }} R-h_{\text {max }}^{2}\right)}{2 h_{\mathrm{p}}} \\
h_{\mathrm{r}}=h-h_{\mathrm{p}}
\end{gathered}
$$

where $h_{\max }$ and $h_{\mathrm{p}}$ in mm were the maximum and residual indentation depth, respectively, as shown in Figure 23. 


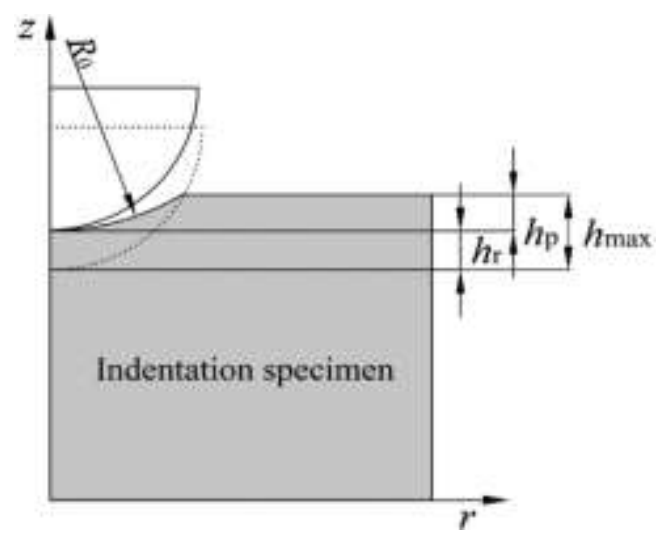

Figure 23 Illustration of the residual indentation surface [10].

It was found from experiments that the relationship between $\ln E_{\text {eff }}$ and $\ln h$ can be described with a linear function, as shown in Figure 24.

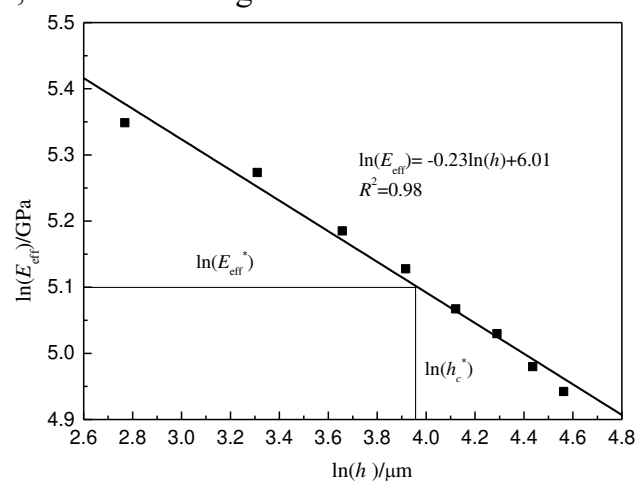

Figure 24 Linear correlation between $\ln E_{\text {eff }}$ and $\ln h$ (for SA508-3)

Same with the previous CIE model, the critical effective Young's modulus $E_{\text {eff }}{ }^{*}$ can be calculated with the Eq.(13), while the $D_{\text {II }}{ }^{*}$ and $E$ were known.

$$
E_{\text {eff }}^{*}=E\left(1-D_{\text {II }}^{*}\right)
$$

Then, critical indentation depth $h_{\mathrm{c}}$ can be determined by fitting curve shown in Figure 24. The fracture toughness can be calculated by Eq. (5) with $h_{\mathrm{c}}$.

\section{Calculation method of impact absorbed energy based on SITs}

\subsection{Stress state analysis of impact test}

According to the displacement and the drop speed of the hammer during the crack arrest test, the Mises stress distribution of impact specimen at the moment $\left(t=1.0 \times 10^{-3} \mathrm{~s}\right)$ is shown in Figure 25. A stress concentration can be seen in the V-notch and impact zone, and the stress gradually decreases from the middle to both sides with the maximum located at the bottom of V-notch. The stress triaxiality extracted from the masked position of V-notch is shown in Figure 26. It can be observed that the stress triaxiality is relatively high near the bottom of the notch in specimen, regarded as a typical high stress triaxiality region $\left(\sigma_{\mathrm{Tr}} \geq 0.4\right)$ $[15,36]$. From $x=0.5 \mathrm{~mm}$ (i.e. the transition between arc and straight line of notch tip), the stress triaxiality decreases sharply $[15,36]$. In this region, the smaller the low stress triaxiality is, the higher degree of constraint from surrounding elastic zone, and more easily to produce shear failure.
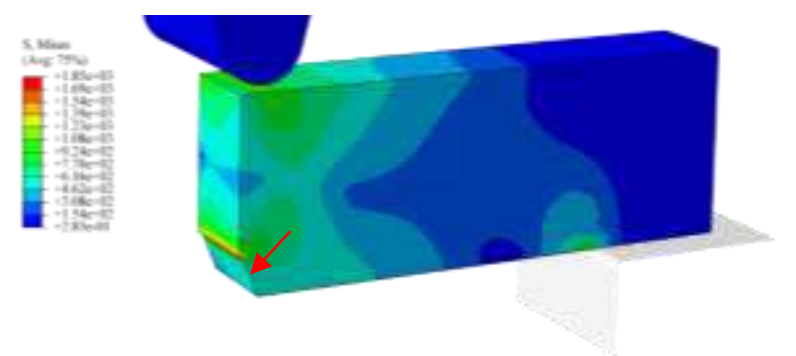

Figure 25 Stress distribution of specimen under impact test

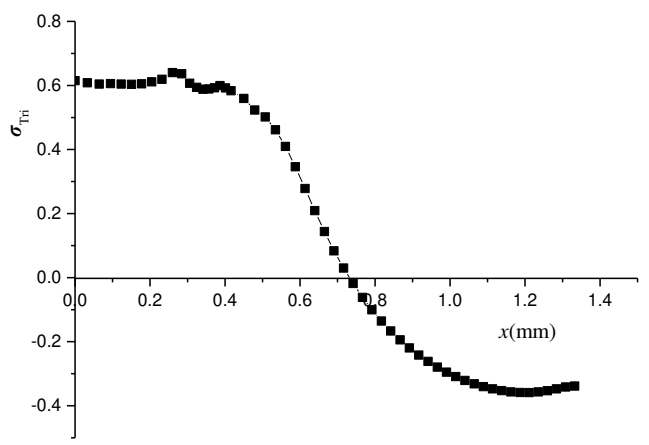

Figure 26 Stress triaxiality along the boundary of V-notch

\subsection{Damage Mechanism Analysis}

SEM observations of section surfaces from crack arrest specimen are shown in Figure 27. The location of crack initiation is consistent with the stress concentration zone at the V-notch tip of the specimen shown in Figure25. Voids and micro-cracks can be seen in front of the crack tip which locate in the high stress triaxiality region mentioned in numerical analysis. According to the micro-mechanics, the initiation of voids can be explained with that the local stress of damage region could well offset the bonding force between particles and matrix. Moreover, its volume increases rapidly, especially in high stress triaxiality region. With the development of voids, the adjacent voids will coalesce, leading to the initiation and propagation of microcracks. The observation of fracture surface for impact test specimen (Q345R) is shown in Figure 28. As presented in the figure, the fracture surface is rough and exhibits obvious dimple morphology. From the numerous voids in the morphology, the damage mechanism of impact specimens is similar with that of Mode I fracture specimens, which can 
be shown as voids accumulation fracture. Combined with the variation of $\sigma_{\text {Tri }}$ in Figure 26, it can be concluded that the fracture surface is mainly caused by the tensile stress under impact test.

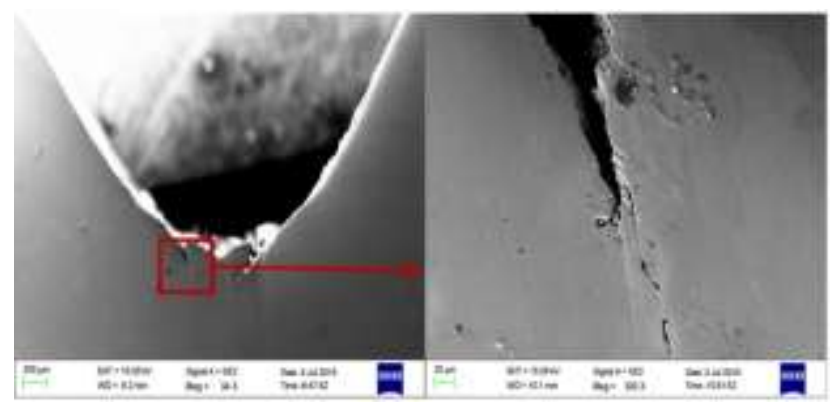

Figure 27 SEM observation of section surface for crack arrest specimen (Q345R)

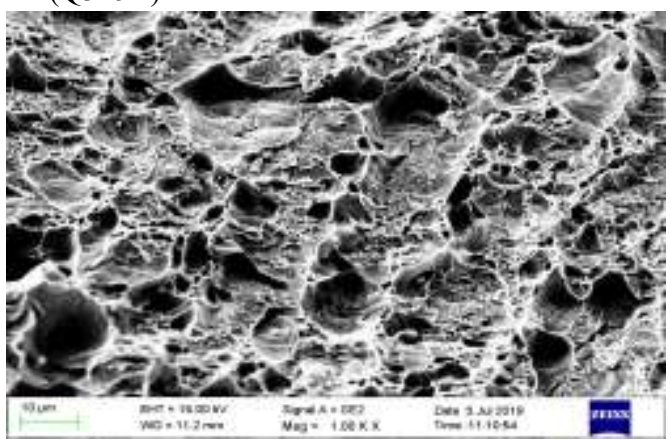

Figure 28 SEM observation of fracture surface for impact test specimen (Q345R)

\subsection{Correlation between dynamic and quasi-static} fracture toughness

The high strain rate loading will affect the yield strength of the specimens, which is known as the strain rate effect. Therefore, variation of the yield strength can reflect the strain rate effect of materials to a certain extent. Based on that, Chaouadi et al. [37] proposed a method to characterize the relationship between dynamic and quasi-static fracture toughness $\left(J_{\mathrm{IC}}\right.$ to $\left.J_{\mathrm{ID}}\right)$ by means of yield strength.

$$
\frac{J_{\mathrm{IC}}}{J_{\mathrm{ID}}} \approx \alpha\left(\frac{\sigma_{\mathrm{YD}}}{\sigma_{\mathrm{YS}}}\right)^{2}
$$

where $\sigma_{\mathrm{YD}}$ in $\mathrm{MPa}$ is dynamic yield strength and $\sigma_{\mathrm{YS}}$ in $\mathrm{MPa}$ is quasi-static yield strength, respectively, and $\alpha$ is the proportion coefficient.

The method was verified by Pan et al. [16] through a large number of experiments on Q345R, from which the constant $\alpha$ was determined as 0.28 (leading to the ratio of $J_{\mathrm{IC}}$ to $J_{\mathrm{ID}}$ $0.44)$.

The engineering stress-strain curves from the dynamic tensile test mentioned in Section 2 are presented in Figure
29, with the corresponding yield strength shown in Table 2 . The average value of the ratio of $\sigma_{\mathrm{YD}}$ to $\sigma_{\mathrm{YS}}$ is 1.258 . Compared with the ratio in reference [35], the ratio of $J_{\text {IC }}$ to $J_{\mathrm{ID}}$ determined from tests in this study is 0.443 (the difference is less than $1 \%$ ).

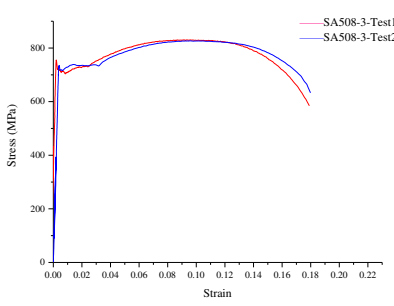

(a) SA508-3

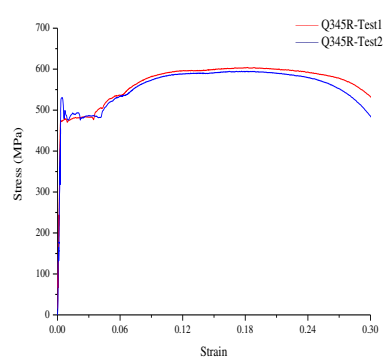

(c) Q345R

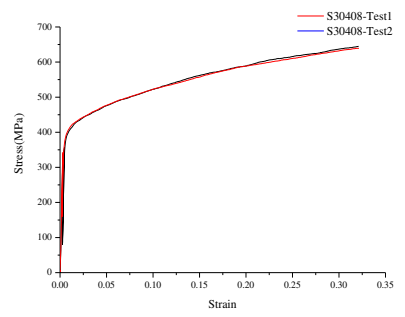

(b) $\mathrm{S} 30408$

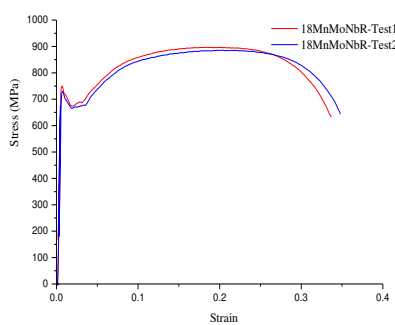

(d) $18 \mathrm{MnMoNbR}$
Figure 29 Stress-strain curve under dynamic tensile test

Table 2 Dynamic and static yield strength of each material

\begin{tabular}{cccc}
\hline Material & $\sigma_{\mathrm{YD}} / \mathrm{MPa}$ & $\sigma_{\mathrm{YS}} / \mathrm{MPa}$ & $\sigma_{\mathrm{YD}} / \sigma_{\mathrm{Ys}}$ \\
\hline SA508-3 & 714 & 560 & 1.275 \\
18MnMoNbR & 843.2 & 680 & 1.24 \\
S30408 & 362 & 278 & 1.30 \\
Q345R & 475 & 373 & 1.273 \\
Average value & & & $\mathbf{1 . 2 5 8}$ \\
\hline
\end{tabular}

\subsection{Correlation between dynamic fracture toughness} and impact absorbed energy

Due to the complexity of dynamic fracture, except for a few problems such as infinite crack body and plane crack of ideal elastic-plastic material, the solution of most problems still has to rely on numerical analysis or empirical formula. However, the finite element method cannot obtain the dynamic fracture parameters of the material. Therefore, the empirical correlation method is the currently main approach to analyze the dynamic parameters [38, 39].

Based on impact tests conducted by Chaouadi [40], the crack initiation location could be determined from the viewpoint of energy, as shown in the Figure 30. As shown in Figure 30, impact absorbed energy $K V_{2}$ is the area under 
the load-displacement curve and energy to crack initiation $K V_{2 \mathrm{i}}$ is the area of purple zone. Through an investigation on the experimental data $[16,40]$, it was founded that the ratio of $K V_{2 \mathrm{i}}$ to $K V_{2}$ is $\eta$, approximately equal to a constant, as shown in Eq.(15).

$$
K V_{2}=K V_{2 \mathrm{i}} / \eta
$$

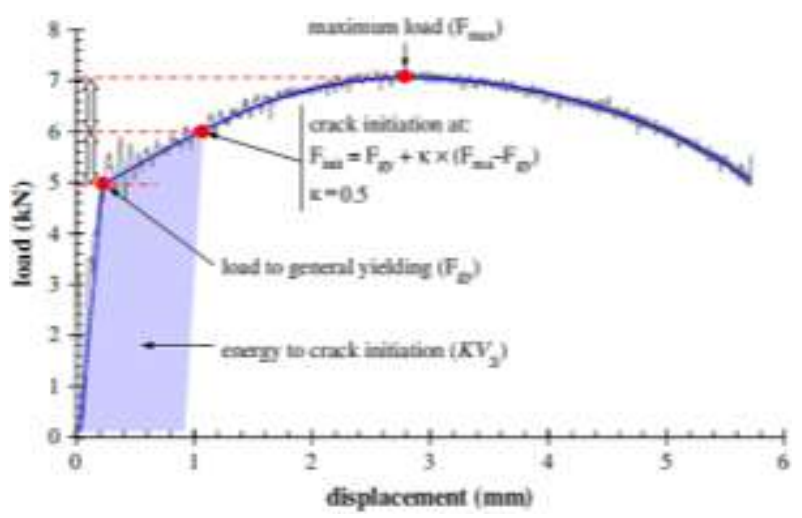

Figure 30 determined of crack initiation energy on the loaddisplacement curve [40]

The Charpy impact tests shown in Section 2.6 yield the $\eta$ around $7 \%$, this value coincides well with those provided in the previous studies $[16,40]$. Thus, the authors try to determine the relationship between dynamic fracture toughness $J_{\mathrm{ID}}$ and impact absorbed energy $K V_{2}$ by correlating $J_{\mathrm{ID}}$ and $K V_{2 \mathrm{i}}$. The specific analysis is as follows.

Comparing the damage mechanism mentioned in Sections 4.2 and 5.2, it is concluded the V-notch tip of impact specimen and crack tip of Mode I fracture specimen was observed in the high stress triaxiality region, and they shared the same fracture mechanism that the damage is caused by the initiation, proliferation and aggregation of voids under tensile stress fields. Therefore, the Charpy impact test can be correlated with Mode I fracture test, which helps to prove that there is a certain quantitative relationship between the dynamic fracture toughness and the crack initiation energy, also explains that it is rational to calculate the impact absorbed energy by SITs.

In Table 3, the quasi-static fracture toughness $J_{\text {IC }}$ is obtained by Mode I fracture test, and the $J_{\mathrm{ID}}$ is calculated with Eq. (14). The crack initiation energy is determined by load-displacement curve from Charpy impact test in Section 2.6. The $K V_{2 \mathrm{i}}-J_{\mathrm{ID}}$ plot and the fitting curve are shown in Figure 31. Based on the Figure 31, The crack initiation energy $K V_{2 \mathrm{i}}$ can be calculated from the fitting curve using $J_{\mathrm{ID}}$, the fitting formula can be expressed as

$$
K V_{2 \mathrm{i}}=0.00036 J_{\mathrm{ID}}^{2}-0.3127 J_{\mathrm{ID}}+79.749
$$

Combined with the Eq. (15), the impact absorbed energy $K V_{2}$ of the material can be obtained. The value of $\eta$ will be discussed in Section 6.

Table 3 fracture toughness and impact crack initiation energy from tests

\begin{tabular}{ccccc}
\hline Material & No. & $J_{\mathrm{IC}} / \mathrm{N} \cdot \mathrm{mm}^{-1}$ & $J_{\mathrm{ID}} / \mathrm{N} \cdot \mathrm{mm}^{-1}$ & $K V_{2 \mathrm{i}} / J$ \\
\hline \multirow{2}{*}{ S30408 } & 1 & 118.60 & 269.55 & 21.76 \\
& 2 & 120.10 & 272.95 & 22.05 \\
SA508-3 & 1 & 146.07 & 331.98 & 16.19 \\
& 2 & 130.39 & 296.34 & 18.26 \\
Q345R & 1 & 175.97 & 399.93 & 11.64 \\
& 2 & 168.00 & 381.82 & 13.10 \\
18MnMoNbR & 1 & 231.00 & 525.00 & 17.46 \\
& 2 & 250.27 & 568.80 & 17.82 \\
\hline
\end{tabular}

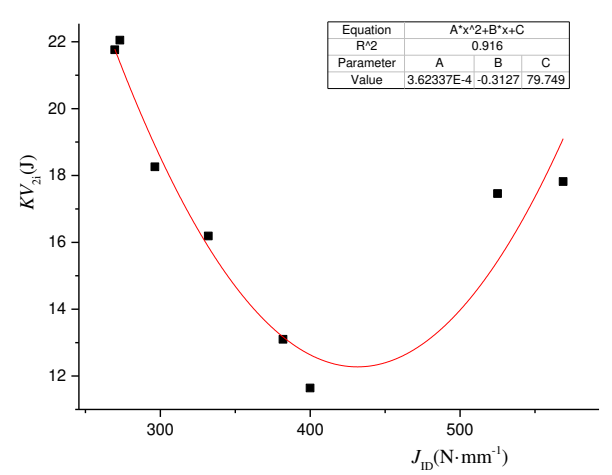

Figure $31 K V_{2 \mathrm{i}^{-}} J_{\text {ID }}$ plot from tests and the fitting curve

\section{Results and discussions}

\subsection{Fracture toughness by modified CIE model}

According to the SITs mentioned in Section 2.4, the effective Young's modulus were calculated by the modified formula Eq. (10) and Pharr-Oliver formula (i.e. $E_{\text {eff }}$ and $E_{\mathrm{PO}}$ ) respectively. Comparison of $E_{\mathrm{PO}}$ and $E_{\text {eff, }}$, with that from tensile test $\left(E_{\mathrm{T}}\right)$ are shown in Table 4 . From the table it was found that the error between $E_{\mathrm{PO}}$ and $E_{\mathrm{T}}$ is up to $30 \%$. However, the error between $E_{\text {eff }}$ and $E_{\mathrm{T}}$ is less than $6 \%$, which proves the validity of the modified effective Young's modulus model.

Table 4 Comparison of $E_{\text {eff }}$ and $E_{\mathrm{PO}}$, with $E_{\mathrm{T}}$

\begin{tabular}{cccccc}
\hline Material & $E_{\mathrm{T}} / \mathrm{GPa}$ & $E_{\mathrm{PO} / \mathrm{GPa}}$ & $\begin{array}{c}\frac{E_{\mathrm{PO}}-E_{\mathrm{T}}}{E_{\mathrm{T}}} \\
/ \%\end{array}$ & $E_{\text {eff }} / \mathrm{GPa}$ & $\begin{array}{c}\frac{E_{\text {eff }}-E_{\mathrm{T}}}{E_{\mathrm{T}}} \\
/ \%\end{array}$ \\
\hline Q345R & 190 & 118 & -37.9 & 180 & -5.2 \\
SA508-3 & 206 & 144 & -30.1 & 199 & -3.4 \\
$18 \mathrm{Mn}$ & 195 & 132 & -32.3 & 200 & 2.6 \\
$\mathrm{~S} 30408$ & 173 & 127 & -26.5 & 182 & 5.2 \\
\hline
\end{tabular}


The load-displacement curves obtained from spherical indentation tests are shown in Figure 32. The loading curve is approximately a straight line, which is the result of the superposition of two nonlinear behaviors in SITs. One is the nonlinearity of the load displacement curve caused by the geometric nonlinearity of the spherical indenter, and the other is the nonlinearity of work-hardening of materials. Combined with the load-displacement curve shown in Figure 32, the fracture toughness is calculated by the previous CIE model and modified CIE model (i.e. $K_{\text {ICP }}$ and $K_{\text {ICM }}$ ). The comparison of $K_{\text {ICP }}$ and $K_{\text {ICM, }}$ with the average results of Mode I fracture test $\left(K_{\mathrm{ICT}}\right)$ in Section 2.5 is shown in Table 5. error of the results of fracture toughness. Compared with the previous CIE model, the modified CIE model is closer to experimental results. Except that the error between $K_{\text {ICM }}$ and $K_{\text {ICT }}$ of $18 \mathrm{MnMoNbR}$ is about $15 \%$, that of other materials is about $5 \%$. In addition, the fracture toughness calculated by the modified CIE model are conservative, which is more desirable in engineering application.

\subsection{Impact absorbed energy by modified CIE model}

The impact absorbed energy $K V_{2 \mathrm{~T}}$ and crack initiation energy $K V_{2 \mathrm{iT}}$ of the four materials are calculated from Charpy impact test, shown in Table 6.

Table 5 Comparison of $K_{\mathrm{ICP}}$ and $K_{\mathrm{ICM}}$, with $K_{\mathrm{ICT}}$

\begin{tabular}{|c|c|c|c|c|c|c|c|c|}
\hline \multirow[b]{2}{*}{ Material } & \multirow[b]{2}{*}{ No. } & Mode I fracture test & \multicolumn{3}{|c|}{ Previous CIE model } & \multicolumn{3}{|c|}{ Modified CIE model } \\
\hline & & $K_{\mathrm{ICT}} / \mathrm{MPa} \cdot \mathrm{m}^{0.5}$ & $h_{\mathrm{c}} / \mathrm{mm}$ & $K_{\mathrm{ICP}} / \mathrm{MPa} \cdot \mathrm{m}^{0.5}$ & $\begin{array}{c}\frac{K_{\text {ICP }}-K_{\text {ICT }}}{K_{\text {ICT }}} \\
\% \\
\end{array}$ & $h \mathrm{c} / \mathrm{mm}$ & $K_{\mathrm{ICM}} / \mathrm{MPa} \cdot \mathrm{m}^{0.5}$ & $\begin{array}{c}K_{\mathrm{ICM}}-K_{\mathrm{ICT}} \\
K_{\mathrm{ICT}} \\
\% \\
\end{array}$ \\
\hline \multirow{2}{*}{ S30408 } & 1 & \multirow{2}{*}{152.33} & 0.097 & 183.41 & 20.40 & 0.063 & 144.27 & -5.29 \\
\hline & 2 & & 0.151 & 231.27 & 51.82 & 0.064 & 147.80 & -2.97 \\
\hline \multirow{2}{*}{ SA508-3 } & 1 & \multirow{2}{*}{171.13} & 0.098 & 231.14 & 35.07 & 0.057 & 175.9 & 2.78 \\
\hline & 2 & & 0.101 & 235.45 & 37.58 & 0.051 & 165.18 & -3.47 \\
\hline \multirow{2}{*}{ Q345R } & 1 & \multirow{2}{*}{176.70} & 0.202 & 248.73 & 40.76 & 0.091 & 165.7 & -6.23 \\
\hline & 2 & & 0.207 & 261.87 & 48.20 & 0.095 & 167.7 & -5.09 \\
\hline \multirow{2}{*}{$18 \mathrm{MnMoNbR}$} & 1 & \multirow{2}{*}{223.00} & 0.158 & 296.32 & 32.87 & 0.071 & 192.78 & -13.55 \\
\hline & 2 & & 0.178 & 317.52 & 42.38 & 0.064 & 184.37 & -17.32 \\
\hline
\end{tabular}

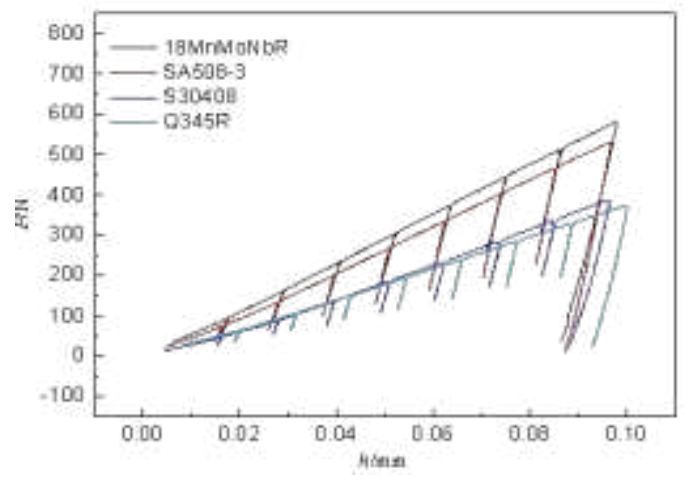

Figure 32 Load-displacement curve obtained from SITs
Table 6 Comparison of $K V_{2 \mathrm{~T}}$ with $K V_{2 \mathrm{iT}}$

\begin{tabular}{ccccc}
\hline Material & No. & $K V_{2 \mathrm{iT}} / \mathrm{J}$ & $K V_{2 \mathrm{~T}} / \mathrm{J}$ & $K V_{2 \mathrm{iT}} / K V_{2 \mathrm{~T}}\left(\eta_{i}\right) \%$ \\
\hline \multirow{2}{*}{ S30408 } & 1 & 21.75757 & 307 & 7.09 \\
& 2 & 22.05407 & 314 & 7.02 \\
SA508-3 & 1 & 16.18597 & 193 & 8.34 \\
& 2 & 18.26295 & 184.5 & 9.90 \\
Q345R & 1 & 11.63808 & 193 & 6.03 \\
& 2 & 13.09879 & 191 & 6.86 \\
18MnMoNbR & 1 & 17.4609 & 237 & 7.37 \\
& 2 & 17.82138 & 227 & 7.85 \\
\hline
\end{tabular}

It is important to note that the range of the ratio $\eta_{i}$ shown in Table 6 is relatively concentrated, the minimum value is $6.03 \%$, and the maximum value is $9.9 \%$. In order to avoid overestimating the material performance in engineering application, the maximum of $\eta_{i}(\eta=9.9 \%)$ is also used to calculate the impact absorption energy. The comparison between $K V_{2 \mathrm{~S}}$ calculated SITs and $K V_{2 \mathrm{~T}}$ obtained from impact tests are shown in Table 7 
Table 7 Comparison between calculated value $K V_{2}$ and experimental value $K V_{2 \mathrm{~T}}$

\begin{tabular}{|c|c|c|c|c|c|c|c|c|}
\hline \multirow[b]{2}{*}{ Material } & \multirow[b]{2}{*}{ No. } & \multirow[b]{2}{*}{$K V_{2 \mathrm{~T}} / \mathrm{J}$} & \multirow[b]{2}{*}{$J_{\mathrm{ID}} / \mathrm{N} \cdot \mathrm{mm}-1$} & \multirow[b]{2}{*}{$K V_{2 \mathrm{i}} / \mathrm{J}$} & \multicolumn{2}{|c|}{$\left(\eta=\eta_{i}\right)$} & \multicolumn{2}{|c|}{$(\eta=9.9 \%)$} \\
\hline & & & & & $K V_{2 \mathrm{~S}} / \mathrm{J}$ & $\begin{array}{c}K V_{2 \mathrm{~S}}-K V_{2 \mathrm{~T}} \\
K V_{2 \mathrm{~T}} \\
/ \%\end{array}$ & $K V_{2 \mathrm{~S}} / \mathrm{J}$ & $\begin{array}{c}K V_{2 \mathrm{~S}}-K V_{2 \mathrm{~T}} \\
K V_{2 \mathrm{~T}} \\
1 \%\end{array}$ \\
\hline \multirow{2}{*}{ S30408 } & 1 & 307 & 260.48 & 22.72 & 320.62 & 4.44 & 231.87 & -24.47 \\
\hline & 2 & 314 & 248.18 & 24.31 & 346.21 & 10.26 & 248.13 & -20.98 \\
\hline \multirow{2}{*}{ SA508-3 } & 1 & 193 & 310.64 & 17.35 & 206.89 & 7.20 & 177.05 & -8.266 \\
\hline & 2 & 184.5 & 273.94 & 21.10 & 213.19 & 15.55 & 215.34 & 16.71 \\
\hline \multirow{2}{*}{ Q345R } & 1 & 193 & 344.34 & 14.76 & 244.75 & 26.81 & 150.60 & -21.97 \\
\hline & 2 & 191 & 336.18 & 15.31 & 223.29 & 16.89 & 156.24 & -18.20 \\
\hline \multirow{2}{*}{$18 \mathrm{MnMoNbR}$} & 1 & 237 & 386.26 & 12.68 & 172.06 & -27.40 & 129.35 & -45.42 \\
\hline & 2 & 227 & 353.29 & 14.21 & 180.98 & -20.27 & 144.98 & -36.13 \\
\hline
\end{tabular}

When $\eta$ is $9.9 \%$, the maximum error between impact absorbed energy determined by SITs and that from the Charpy impact test is $45.42 \%$. However, there are only two sets of data are larger than $30 \%$, both of them are less than the experimental value, indicating that the results are in accord with safety requirement of engineering application. When the impact absorbed energy was calculated from SITs with an application of the material's own crack initiation energy ratio (i.e. $\eta=\eta_{\mathrm{i}}$ ), the minimum error is $4.44 \%$, the maximum is $27.4 \%$, while 6 of 8 sets of data are within $21 \%$. From the results, it can be concluded that it is feasible to estimate the impact absorbed energy by spherical indentation tests, but the calculation accuracy is still needed to discuss. The usability of this method will be further improved after establishment of a comprehensive database.

\section{Conclusions}

Aimed at the problem that conventional approaches for mechanical property determination all need destructive sampling, which may be improper for in-service structures, a method to determine the quasi-static fracture toughness and impact absorbed energy from SITs was proposed in this study. The stress status and damage mechanics of SIT, mode I fracture and Charpy impact tests were first investigated through FE calculations and SEM observations, respectively. Then, the widely used CIE model in quasi-static fracture toughness determination from SITs was modified. The quasi-static fracture toughness determined from the CIE model was used in evaluating the impact absorbed energy by means of the dynamic fracture toughness and crack initiation energy. Effectiveness of the new proposed method was verified through experiments on four kinds of steels, i.e. Q345R, SA508-3, 18MnMoNbR, and S30408. The following remarks are drawn from the investigations mentioned above.

(1) The damage in mode I fracture origins from the void nucleation, growth, and coalescence at a high stress triaxiality, which is similar like that from uniaxial tensile tests, while the indentation damage sources from the dislocation pile-up at a low stress triaxiality, which is similar like that from pure shear tests. Therefore, the SIT and mode I fracture can be correlated by induced the relationship of uniaxial tensile and pure shear tests.

(2) From cyclic-loading tensile tests on the four experiment used metals, it was found that the critical tensile damage variable varies between 0.20 to 0.23 (conservatively set as 0.2 ). Correspondingly, the critical shear damage variable, which is applicable to SITs, is 0.25 .

(3) Compared with the previous CIE model, the modified CIE model takes not only the damage mechanism into consideration, but also more effective in quasi-static fracture toughness calculation (with the maximum error decreases from $51.82 \%$ to $-17.32 \%$ ).

(4) When the impact absorbed energy was calculated from SITs with an application of the material's own crack initiation energy ratio (i.e. $\eta=\eta_{\mathrm{i}}$ ), the maximum error is around $25 \%$. The calculation accuracy may be further improved when a more comprehensive crack initiation energy ratio database is developed. In this case, the SIT can be considered as an alternative method for evaluating the impact absorbed energy.

\section{Declaration}

\section{Acknowledgements}

Not applicable

\section{Funding}

Supported by National Natural Science Foundation of China, the investigation of the mechanism and universality of material mechanical proprieties tested by automated ball indentation method (Grant No. 51475269), National Key Research and Development Project, research on the key 
technology of micro damage testing of material properties and development of testing instrument (Grant No. 2016YFF0203005).

\section{Availability of data and materials}

The datasets supporting the conclusions of this article are included within the article.

\section{Authors' contributions}

The author' contributions are as follows: Tai-Rui Zhang and Wei-Qiang Wang were in charge of the whole trial; Jian-Xun Li wrote the manuscript; Ji-Rui Cheng and Shang Wang assisted with sampling and laboratory analyses. All authors read and approved the final manuscript.

\section{References}

[1] Zhang T, Wang S, Wang W: An energy-based method for flow property determination from a single-cycle spherical indentation test (SIT). International Journal of Mechanical Sciences 2020, 171.

[2] Chen H, Cai LX: An elastoplastic energy model for predicting the deformation behaviors of various structural components. Applied Mathematical Modelling 2019, 68:405-421.

[3] Yu F, Ben Jar PY, Hendry MT: Indentation for fracture toughness estimation of high-strength rail steels based on a stress triaxialitydependent ductile damage model. Theoretical and Applied Fracture Mechanics 2018, 94:10-25.

Wu S, Xu T, Song M, Guan K: Mechanical properties characterisation of welded joint of austenitic stainless steel using instrumented indentation technique. Materials at High Temperatures 2016, 33:270-275.

Ghosh S, Prakash RV: Study of damage and fracture toughness due to influence of creep and fatigue of commercially pure copper by monotonic and cyclic indentation. Metallurgical and Materials Transactions aPhysical Metallurgy and Materials Science 2013, 44A:224-234.

Byun TS, Kim JW, Hong JH: A theoretical model for determination of fracture toughness of reactor pressure vessel steels in the transition region from automated ball indentation test. Journal of Nuclear Materials 1998, 252:187-194.

Anderson TL: Fracture Mechanics. Taylor and Francis, 2017.

[8] Haggag FM, Byun TS, Hong JH, Miraglia PQ, Murty KL: IndentationEnergy-to-Fracture (IEF) parameter for characterization of DBTT in carbon steels using nondestructive Automated Ball Indentation (ABI) technique. Scripta Materialia 1998, 38:645-651.

\section{Competing interests}

The authors declare no competing financial interests.

\section{Consent for publication}

Not applicable

\section{Ethics approval and consent to participate} Not applicable

Steel Fracture Toughness by Automated Indentation Testing Method. Mechatronics. 2017,23(06):23-29. (in Chinese).

Lee JS, Jang J, Lee BW, Choi Y, Lee SG, Kwon D: An instrumented indentation technique for estimating fracture toughness of ductile materials: A critical indentation energy model based on continuum damage mechanics. Acta Materialia 2006, 54:1101-1109.

Li J, Li F, Ma X, Wang Q, Dong J, Yuan Z: A strain-dependent ductile damage model and its application in the derivation of fracture toughness by micro-indentation. Materials \& Design 2015, 67:623-630.

Ghosh S, Das G: Effect of pre-strain on the indentation fracture toughness of high strength low alloy steel by means of continuum damage mechanics. Engineering Fracture Mechanics 2012, 79:126-137.

Han N, Zhang X, Liu S, Ke B, Xin X: Effects of pre-stretching and ageing on the strength and fracture toughness of aluminum alloy 7050. Materials Science and Engineering a-Structural Materials Properties Microstructure and Processing 2011, 528:3714-3721.

Andersson H: Analysis of a model for void growth and coalescence ahead of a moving crack tip. Journal of the Mechanics and Physics of Solids $1977,25: 217-233$.

Bao YB, Wierzbicki T: A comparative study on various ductile crack formation criteria. Journal of Engineering Materials and TechnologyTransactions of the Asme 2004, 126:314-324.

Pan J H. Dynamic Fracture Behavior of Pressure Vessel Metal Materials under Impact Loads. Anhui: University of Science and Technology of China, 2013

Barsom JM, Rolfe ST: Correlations between $\mathrm{K}_{\text {sub }} \mathrm{I}_{\mathrm{c}}$ and charpy V-notch test results in the transition-temperature range. Impact Testing of Metals $1970,3: 281-302$

[18] Hübner P, Pusch G: Correlations between Charpy energy and crack 
initiation parameters of the J-integral-concept. European Structural Integrity Society 2002, 30:289-295.

Smith RJ, Horn AJ, Sherry AH: Relating Charpy energy to fracture toughness in the lower transition region using a Weibull stress dependent energy scaling model. International Journal of Pressure Vessels and Piping 2018, 166:72-83.

Zhang T, Wang S, Wang W: A comparative study on fracture toughness calculation models in spherical indentation tests (SITs) for ductile metals. International Journal of Mechanical Sciences 2019, 160:114-128.

Zhang T, Wang S, Wang W: A unified energy release rate based model to determine the fracture toughness of ductile metals from unnotched specimens. International Journal of Mechanical Sciences 2019, 150:3550.

Shi M Z, Huang Z Q, Lu R K, Study of the Relation Between the Simple Tension Damage Factor D1c and Pure Shear Damage Factor. Journal of Zhejiang University(Natural Science). 1988(06):25-29.
GB713-2014, Steel plates for boilers and pressure vessels, Standardization Administration of the PRC, Beijing, PR China.

ASTM A508 / A508M-17. Standard specification for quenched and tempered vacuum-treated carbon and alloy steel forgings for pressure vessels. West Conshohocken, PA: ASTM International; 2017.

GB/T 12771-2019, Welded stainless steel pipes for liquid delivery, Standardization Administration of the PRC, Beijing, PR China.

GB/T 228.1-2010, Metallic materials-tensile testing part 1: method of test at room temperature, Standardization Administration of the PRC, Beijing, PR China.

GB/T 21143-2014, Metallic materials-unifified method of test for determination of quasistatic fracture toughness, Standardization Administration of the PRC, Beijing, PR China

GB/T 229-2007, Metallic materials - Charpy pendulum impact test method, Standardization Administration of the PRC, Beijing, PR China. Zhang T, Wang S, Wang W: Improved methods to determine the elastic modulus and area reduction rate in spherical indentation tests. Materials Testing 2018, 60:355-362.

Zener C. Fracturing of metals. Cleveland OH: American Society of Metals, 1948.

Bonora N: A nonlinear CDM model for ductile failure. Engineering Fracture Mechanics 1997, 58:11-28.

Sritharan T, Chandel RS: Phenomena in interrupted tensile tests of heat treated aluminium alloy 6061. Acta Materialia 1997, 45:3155-3161.

Lemaitre J: A continuous damage mechanics model for ductile fracture. Journal of Engineering Materials and Technology-Transactions of the

Asme 1985, 107:83-89.

[34]

Oliver WC, Pharr GM: Measurement of hardness and elastic modulus by instrumented indentation: Advances in understanding and refinements to methodology. Journal of Materials Research 2004, 19:3-20.

Oliver WC, Pharr GM: An improved technique for determining hardness and elastic-modulus using load and displacement sensing indentation experiments. Journal of Materials Research 1992, 7:1564-1583.

Bao YB, Wierzbicki T: On fracture locus in the equivalent strain and stress triaxiality space. International Journal of Mechanical Sciences 2004, 46:81-98

Chaouadi R: An energy-based crack extension formulation for crack resistance characterization of ductile materials. Journal of Testing and Evaluation 2004, 32:469-475.

Tomasek R, Mares V, Horsak L: Fracture toughness and Charpy impact test of MIM steels and correlation of results by KIC- CVN relationships. Key Engineering Materials 2019, 810:1-6.

Li HF, Duan QQ, Zhang P, Zhou XH, Wang B, Zhang ZF: The quantitative relationship between fracture toughness and impact toughness in highstrength steels. Engineering Fracture Mechanics 2019, 211:362-370.

Chaouadi R, Puzzolante JL: Loading rate effect on ductile crack resistance of steels using precracked Charpy specimens. International Journal of Pressure Vessels and Piping 2008, 85:752-761.

\section{Biographical notes}

Jian-Xun Li, born in 1993, is currently a PhD candidate at school of mechanical engineering, Shandong University, China. He received his graduate degree from Chinese University of Petroleum, China, in 2019. His research interests include nondestructive testing and ultra-high cycle fatigue.

Tel: +86-18306483260; E-mail: 963577095@qq.com

Tai-Rui Zhang, born in 1991, received his $\mathrm{PhD}$ at the School of Mechanical Engineering, Shandong University, China, 2018. His research interest includes materials testing and mechanics.

E-mail: 1295408193@qq.com

Shang-Wang, born in 1994, received his master degree at the School of Mechanical Engineering, Shandong University, China, 2018. Her main research areas include engineering failure analysis and the determination of fracture toughness through instrumented E-mail: wangshang_sdu@163.com

Ji-rui Cheng, born in 1994, received his master degree at School of Mechanical Engineering, Shandong University, China, in 2019. E-mail: jerry.chengjirui@foxmail.com

Wei-Qiang Wang, born 1959, received his $\mathrm{PhD}$ at the School of Mechanical and Power Engineering, East China University of Science and Technology, Shanghai, China in 1990. Currently, he is 
Professor at the School of Mechanical Engineering Shandong University, Jinan, China. His research includes engineering failure analysis, supercritical fluid technology, and materials testing

Tel: +86-0531-8839-5100; E-mail: sduefascf@163.com

\section{Appendix}

Appendix and supplement both mean material added at the end of a book. An appendix gives useful additional information, but even without it the rest of the book is complete: In the appendix are forty detailed charts. A supplement, bound in the book or published separately, is given for comparison, as an enhancement, to provide corrections, to present later information, and the like: A yearly supplement is issue. 
Figures

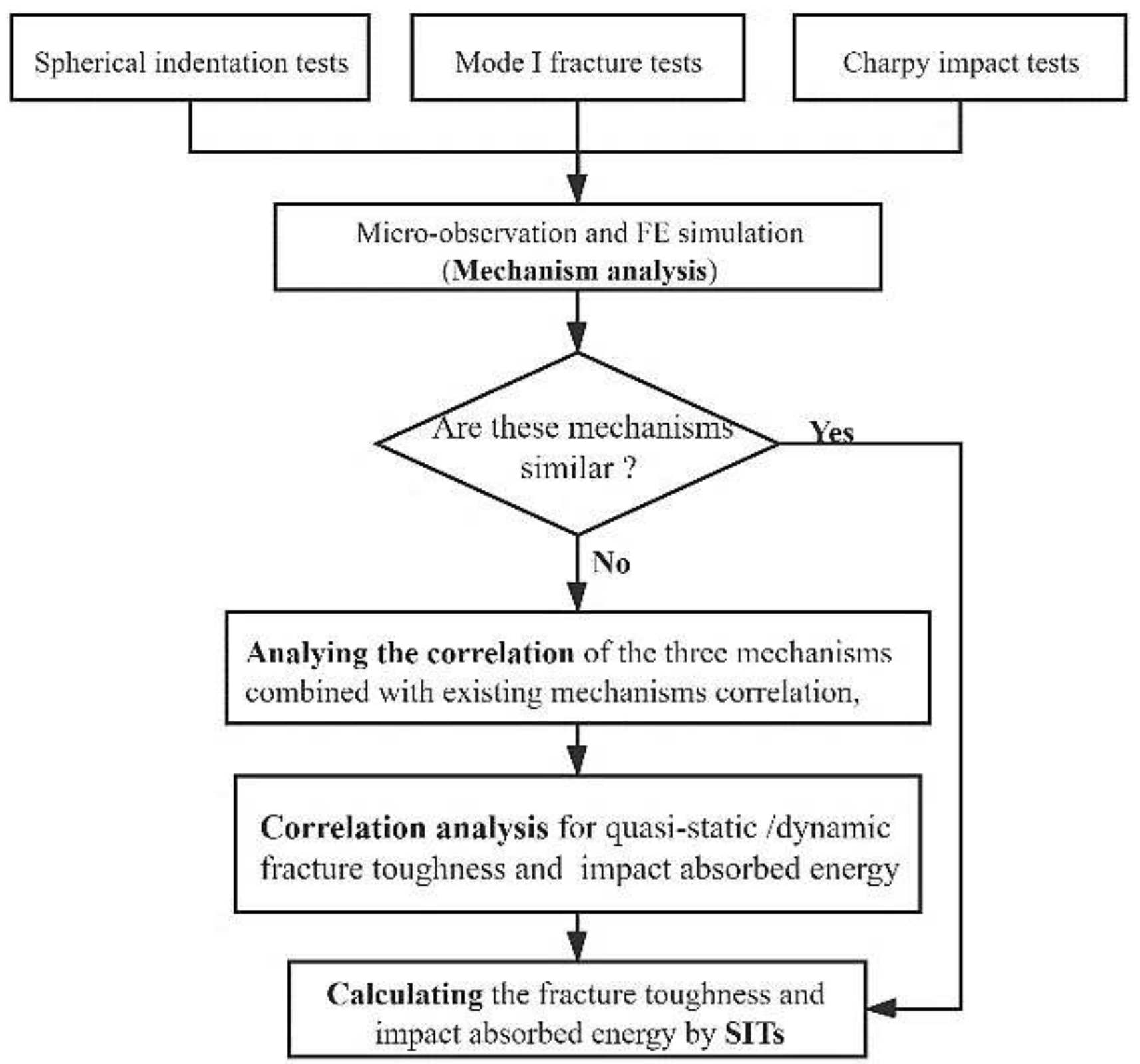

Figure 1

The main technical route 


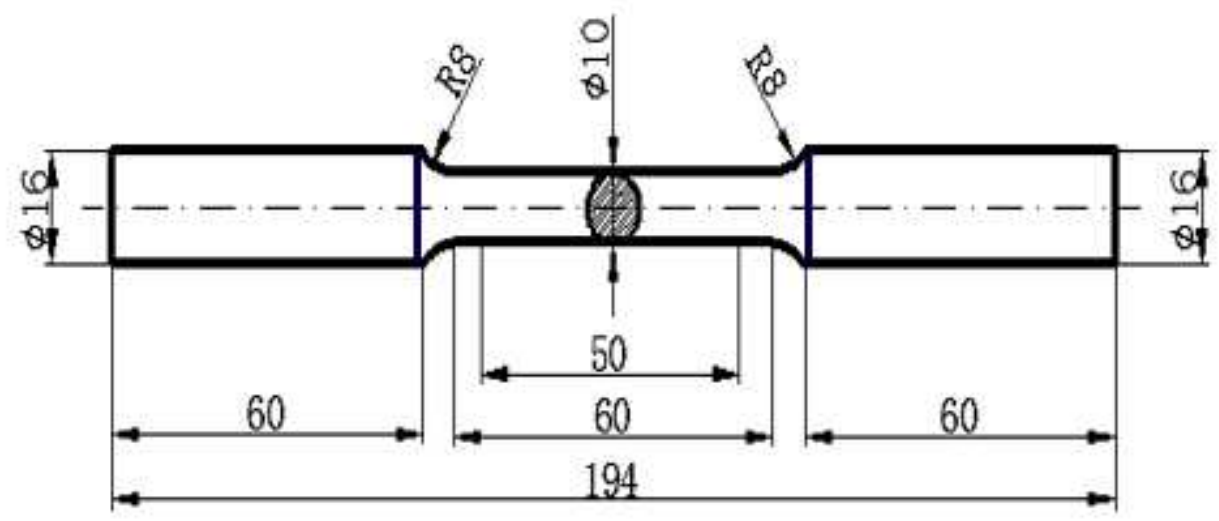

Figure 2

Configuration of the quasi-static tensile specimen.

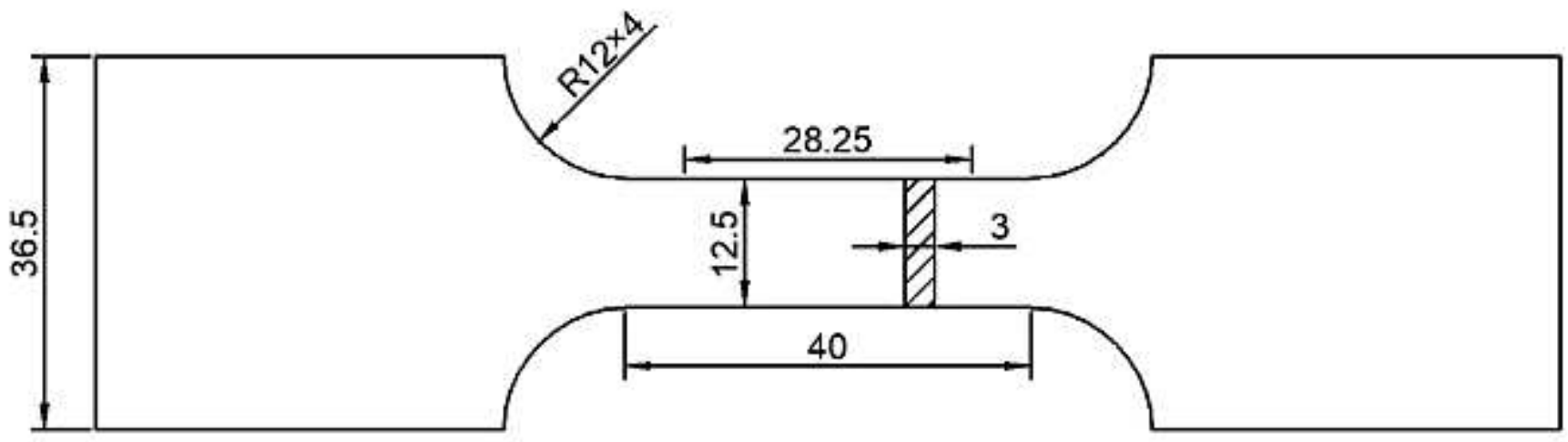

Figure 3

Configuration of the dynamic tensile specimen 


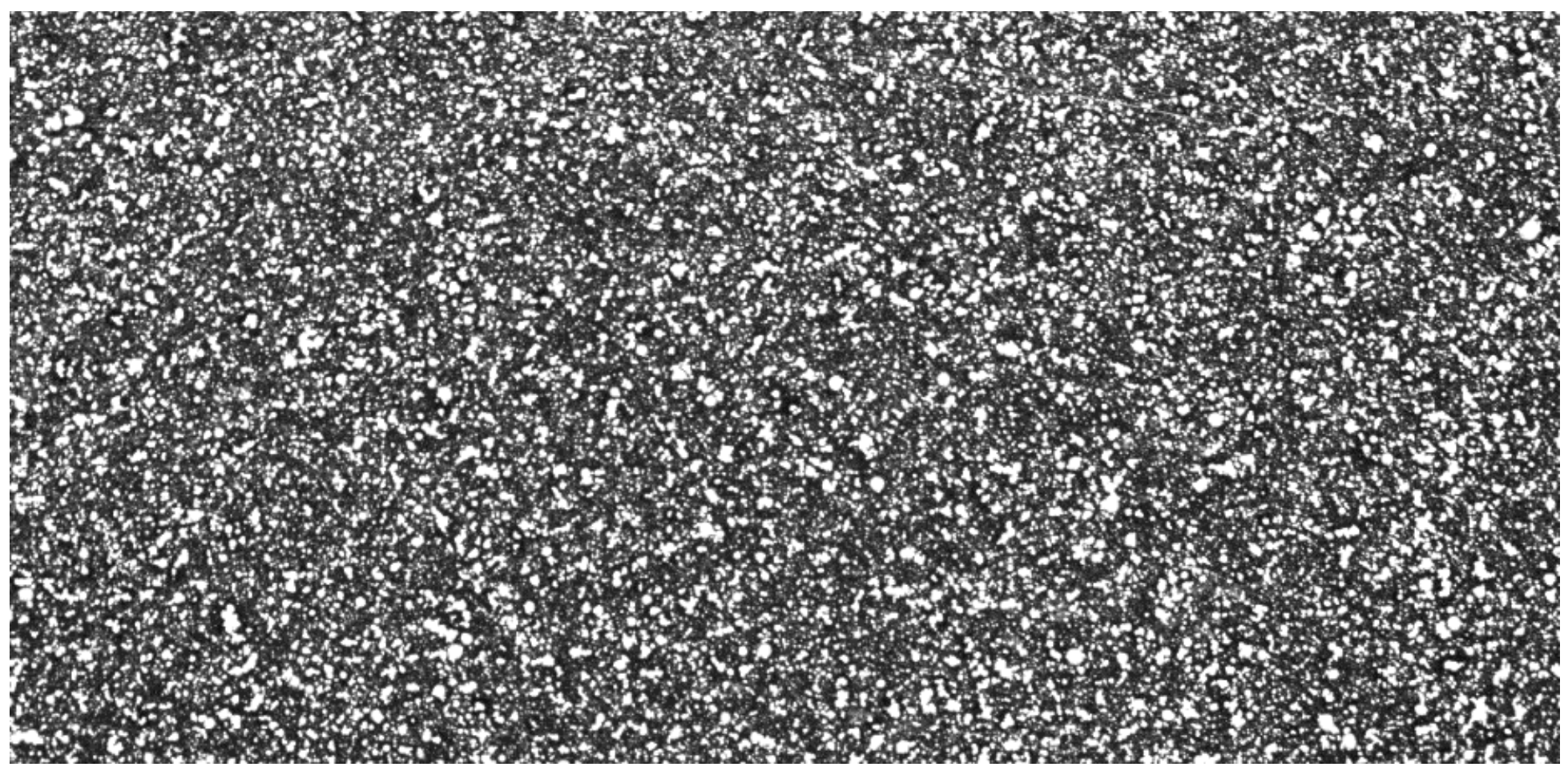

Figure 4

Typical specimen speckle photograph 


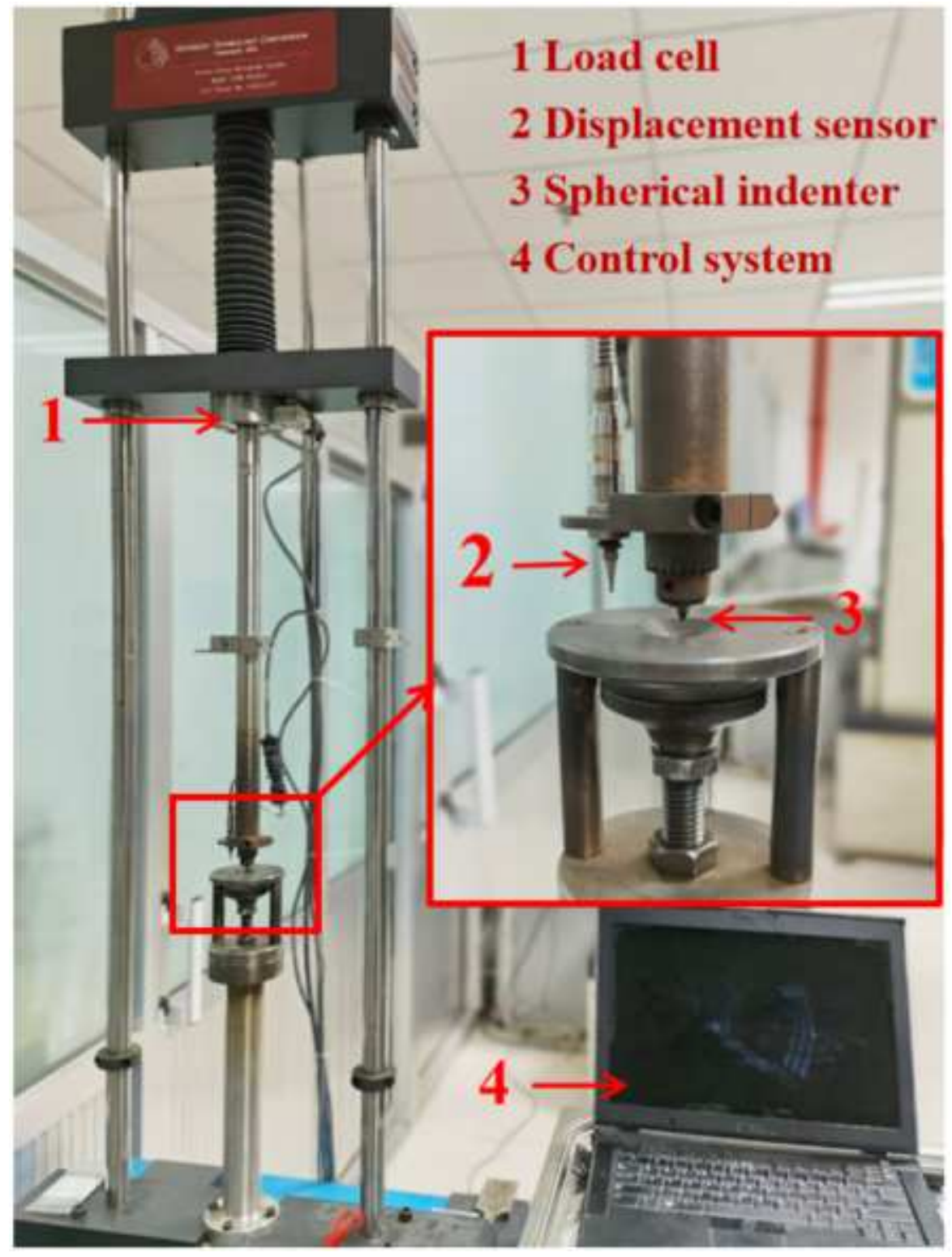

Figure 5

Stress-Strain Microprobe system B4000 


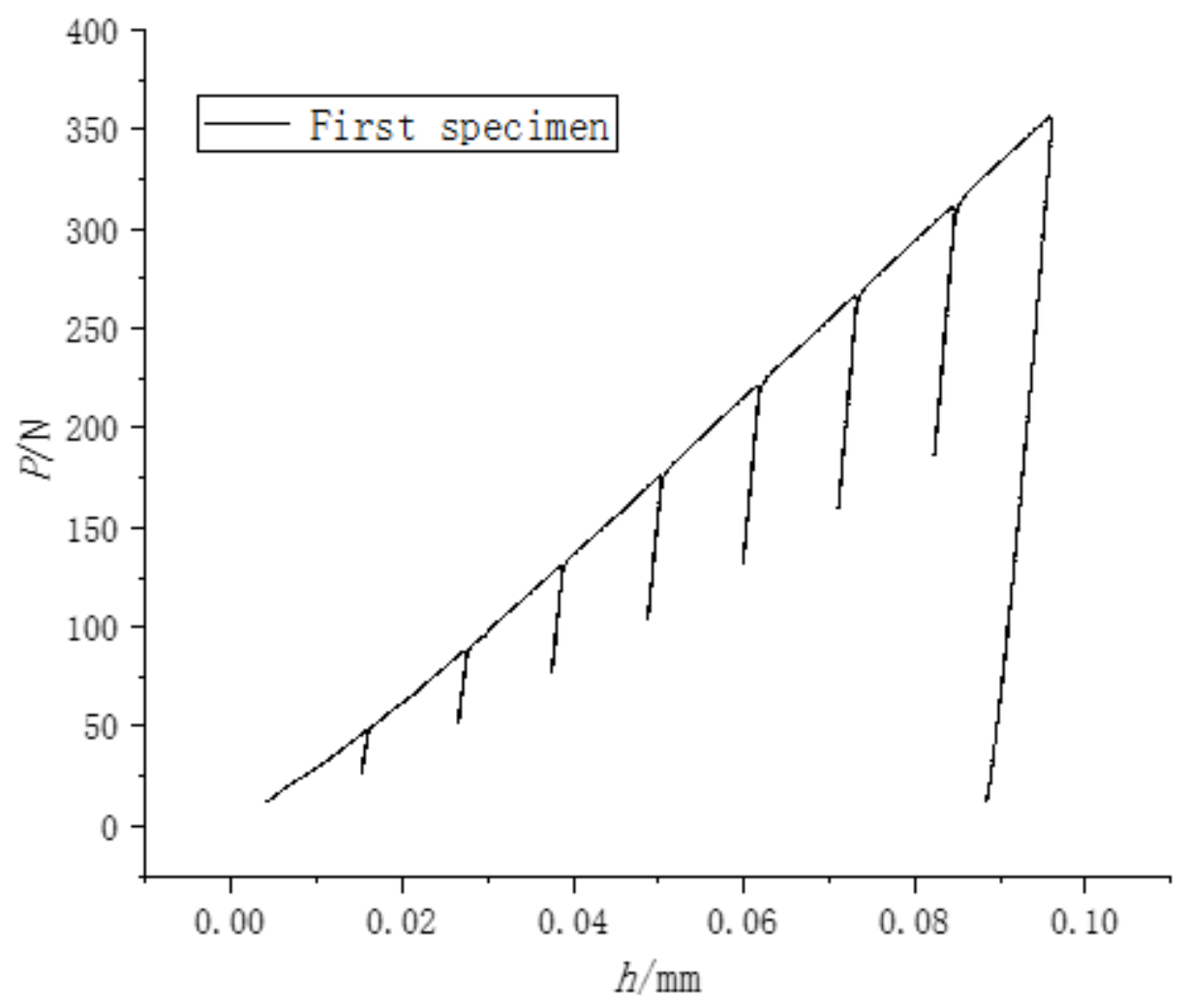

Figure 6

Load-depth curve of from SITs
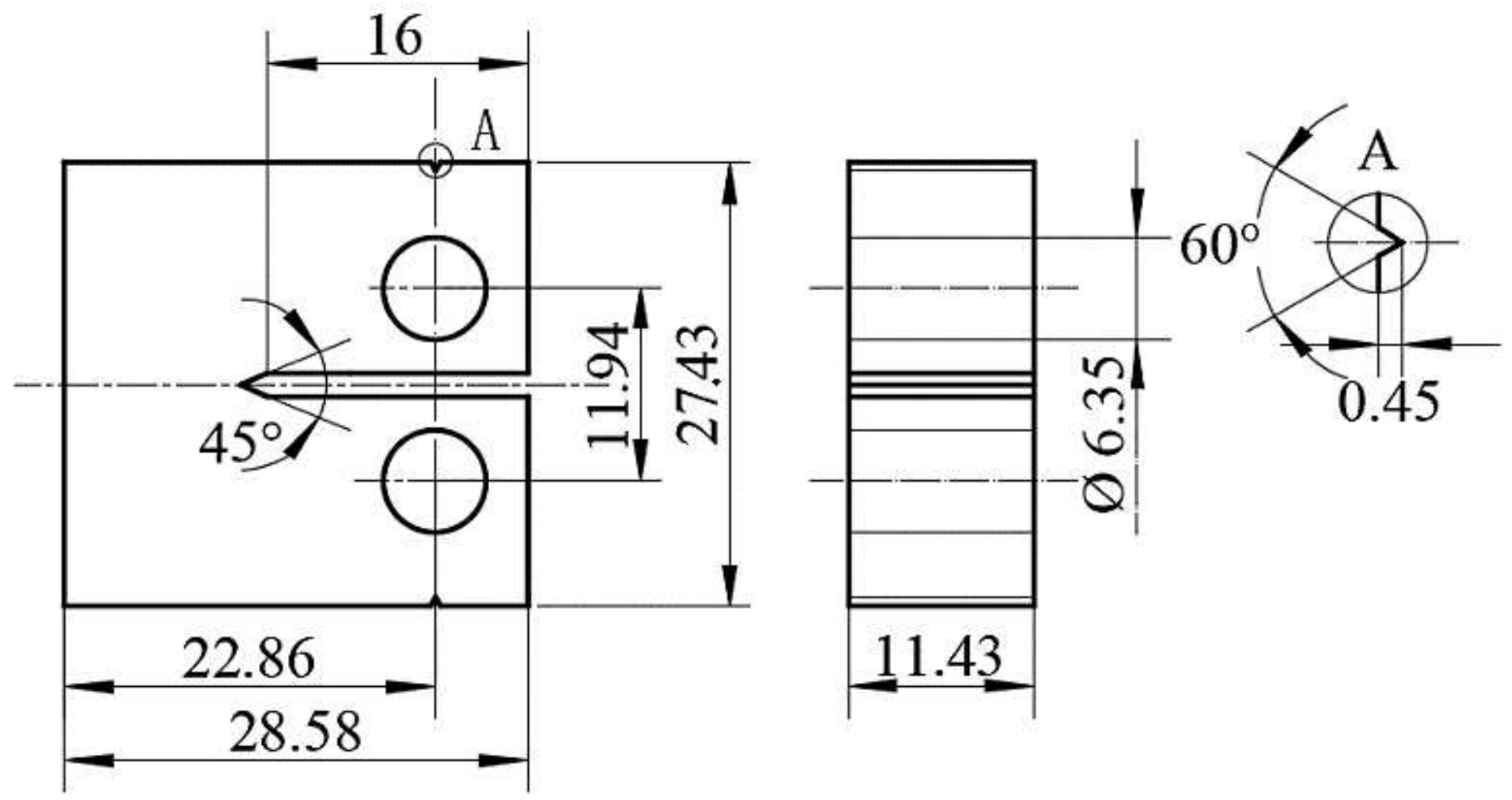

Figure 7 

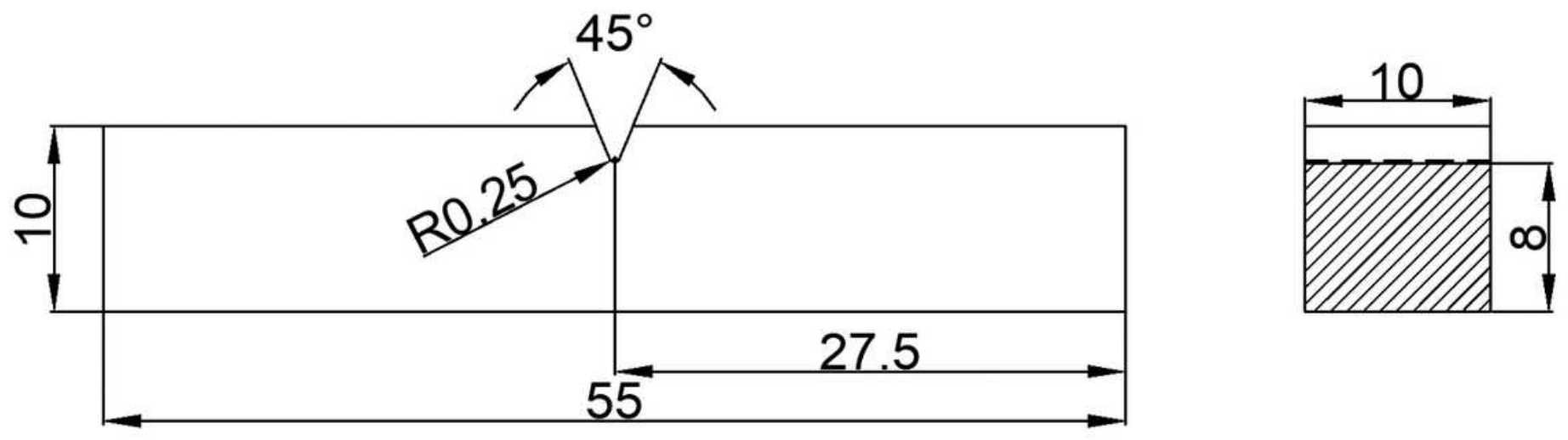

Figure 8

Configuration of the Charpy impact test specimen
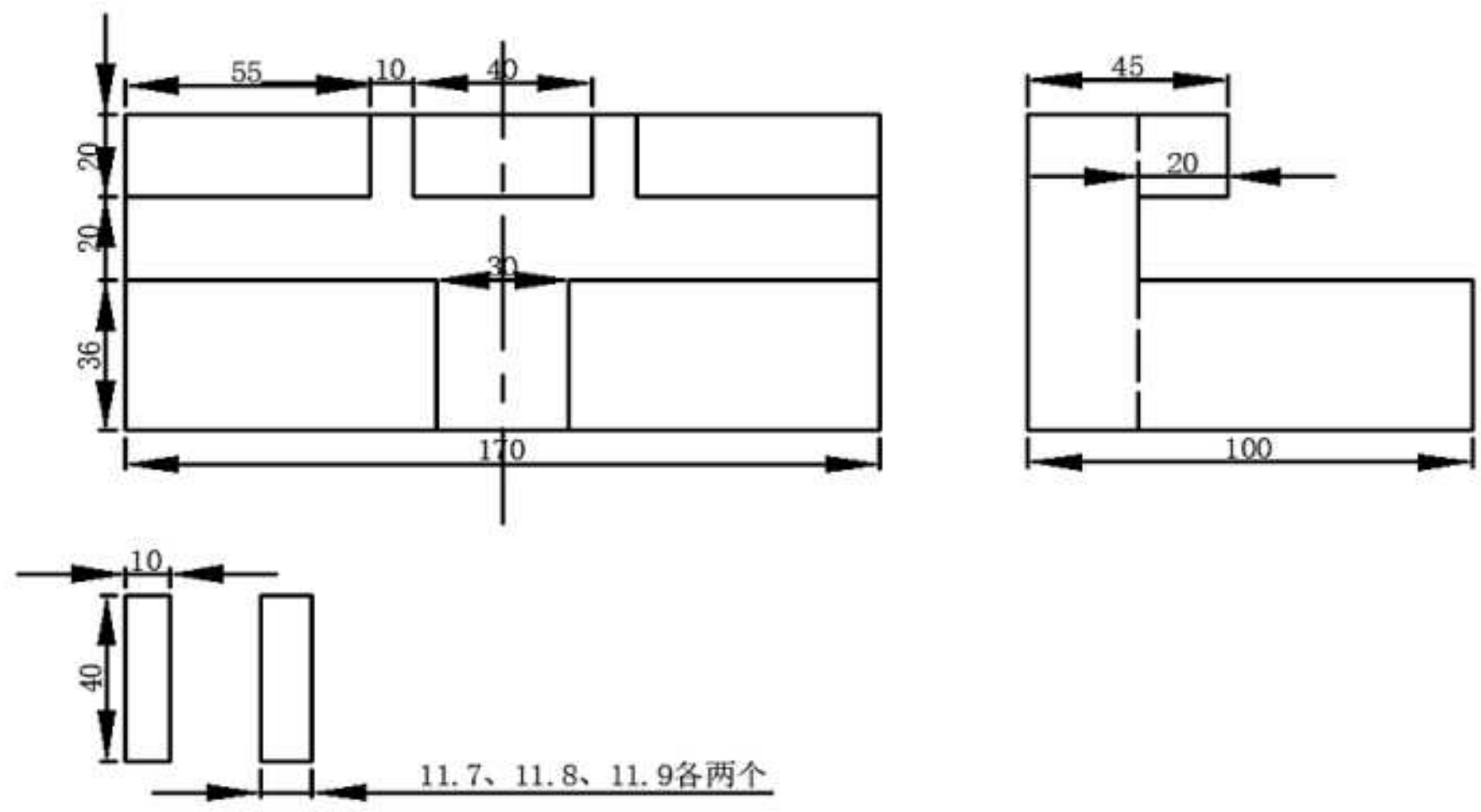

Figure 9

Configuration of the crack arrest tooling 

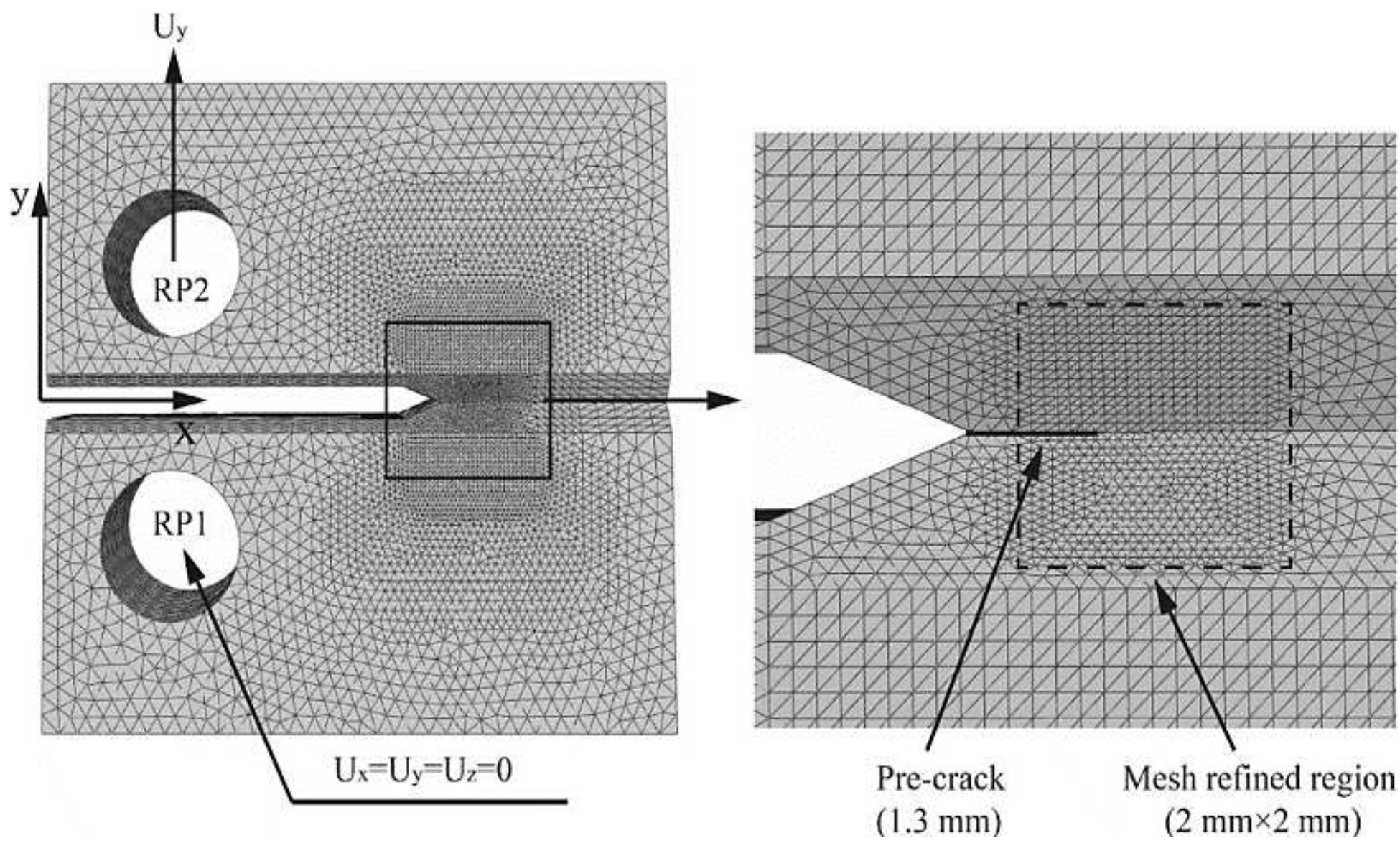

Figure 10

Illustration of the FE model of Mode I fracture tests 


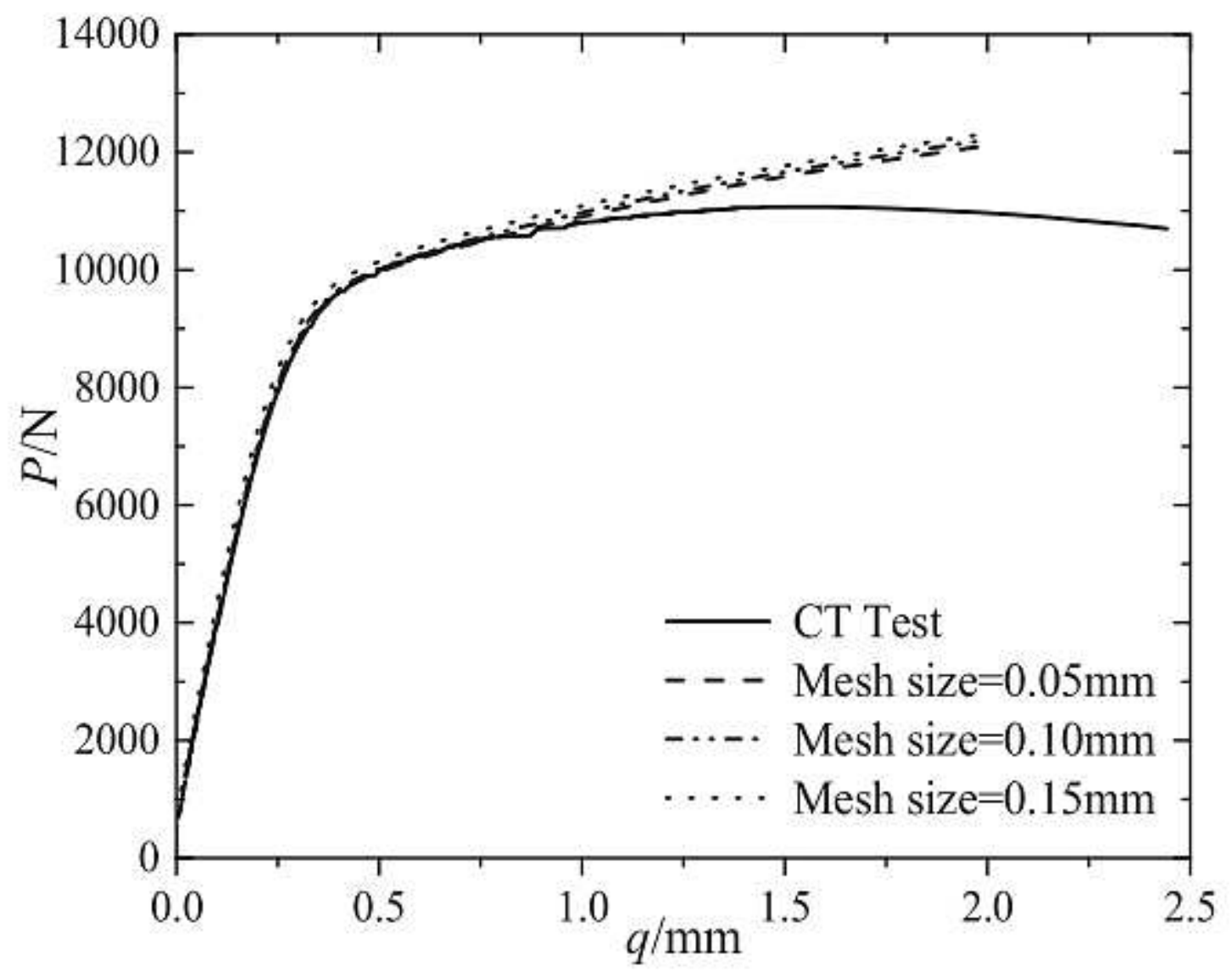

Figure 11

Comparison of the $\mathrm{P}-\mathrm{q}$ curves from tests and FEA
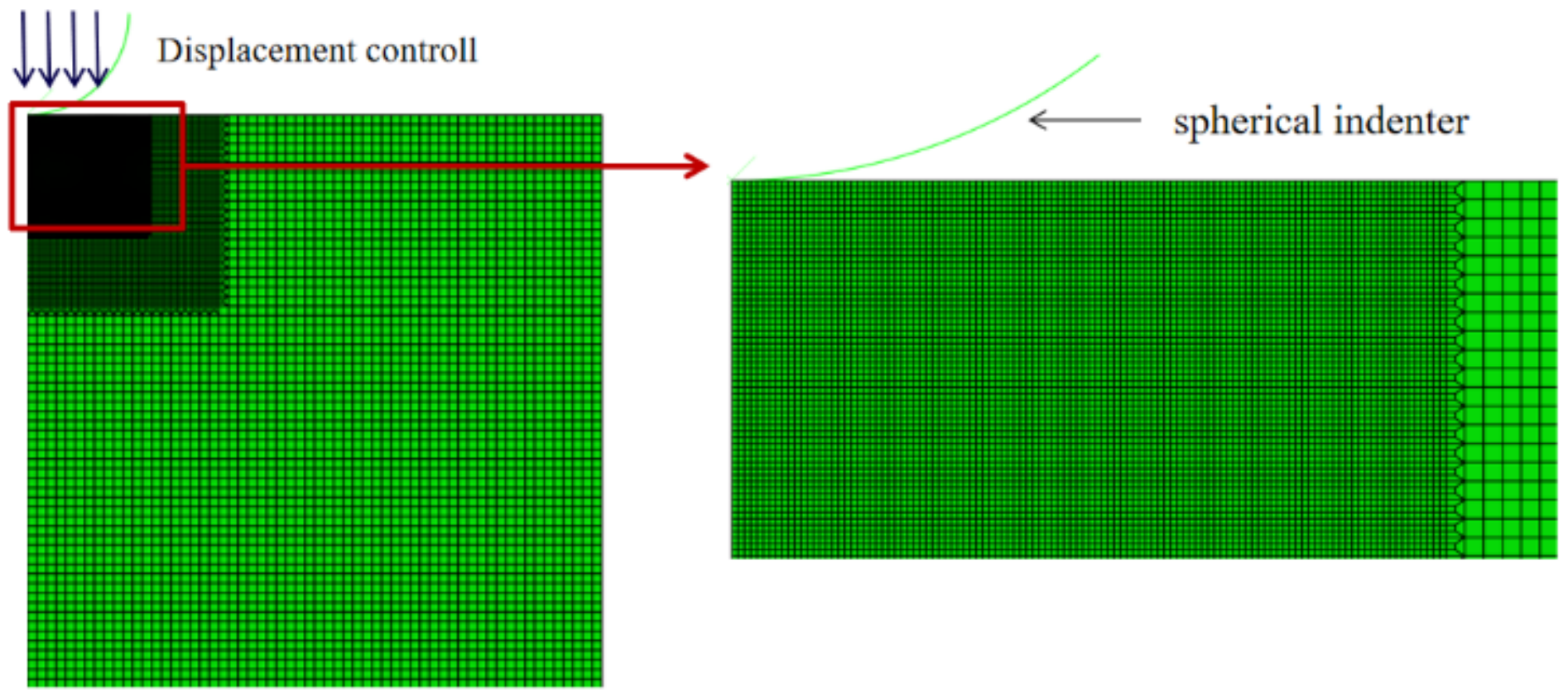

Figure 13

Illustration of the FE modeling of SITS 

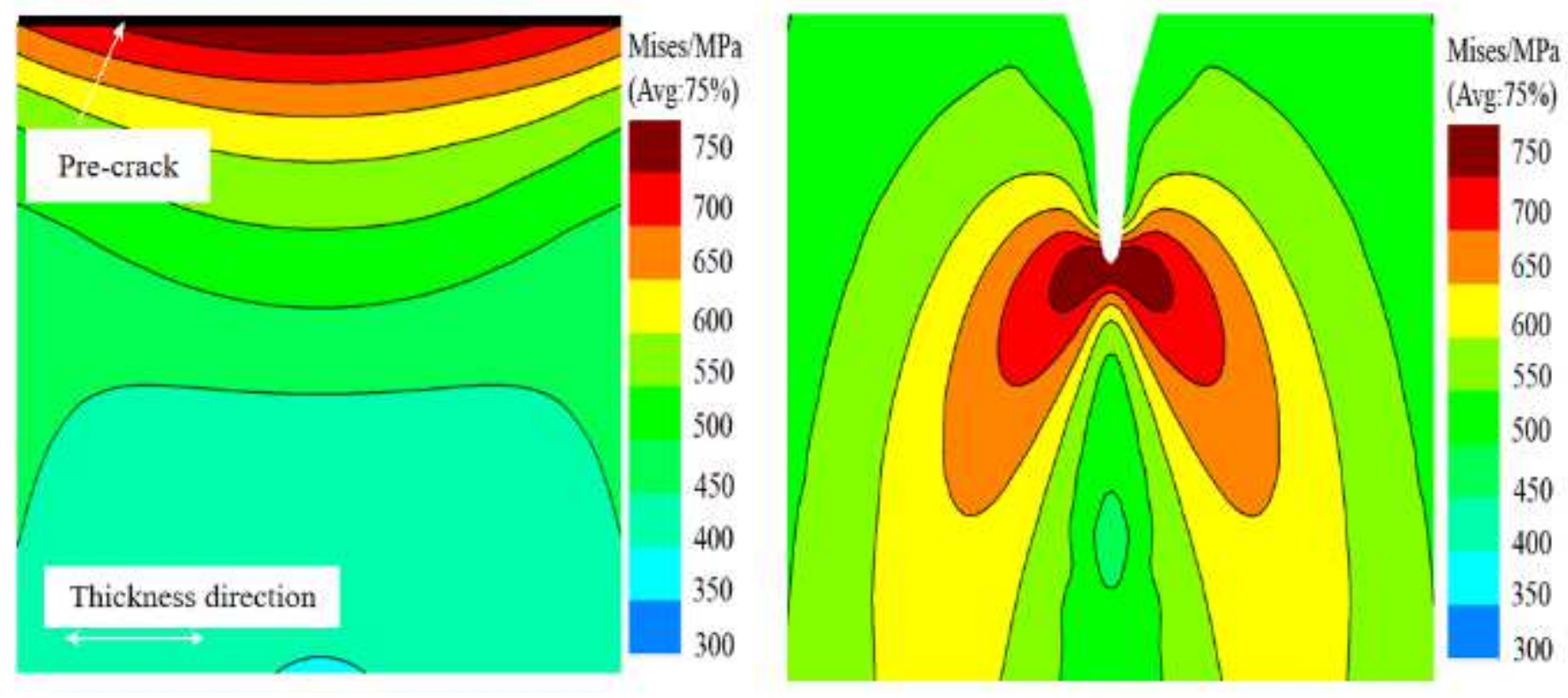

\section{Figure 14}

(a囚Section in thickness direction $₫ \mathrm{~b} \otimes$ Middle section Mises stress distribution of CT specimen $(\mathrm{q}=0.75 \mathrm{~mm})$

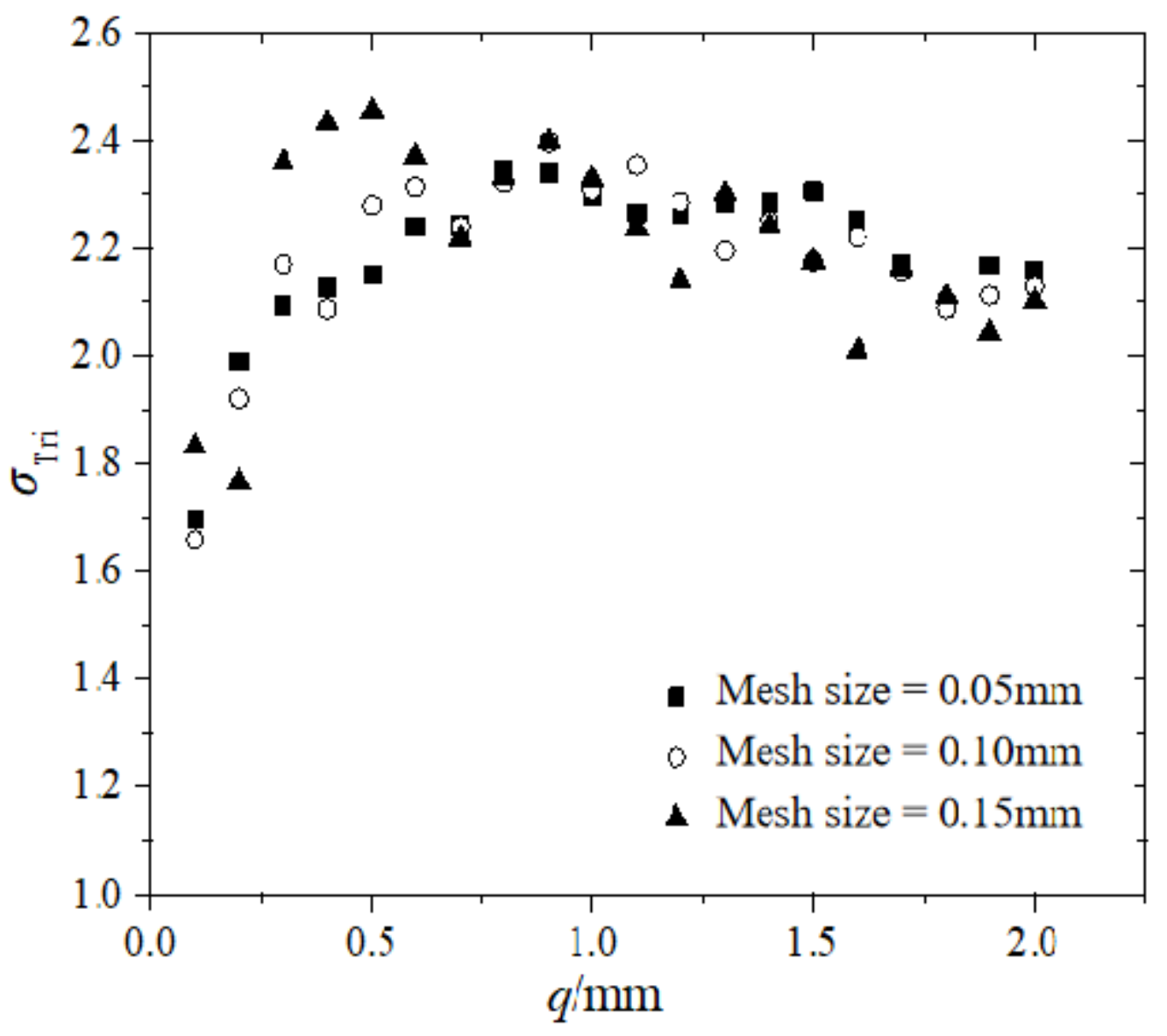

Figure 15

Variation of $\sigma$ Tri with $q$ at the crack tip under Mode I loading 


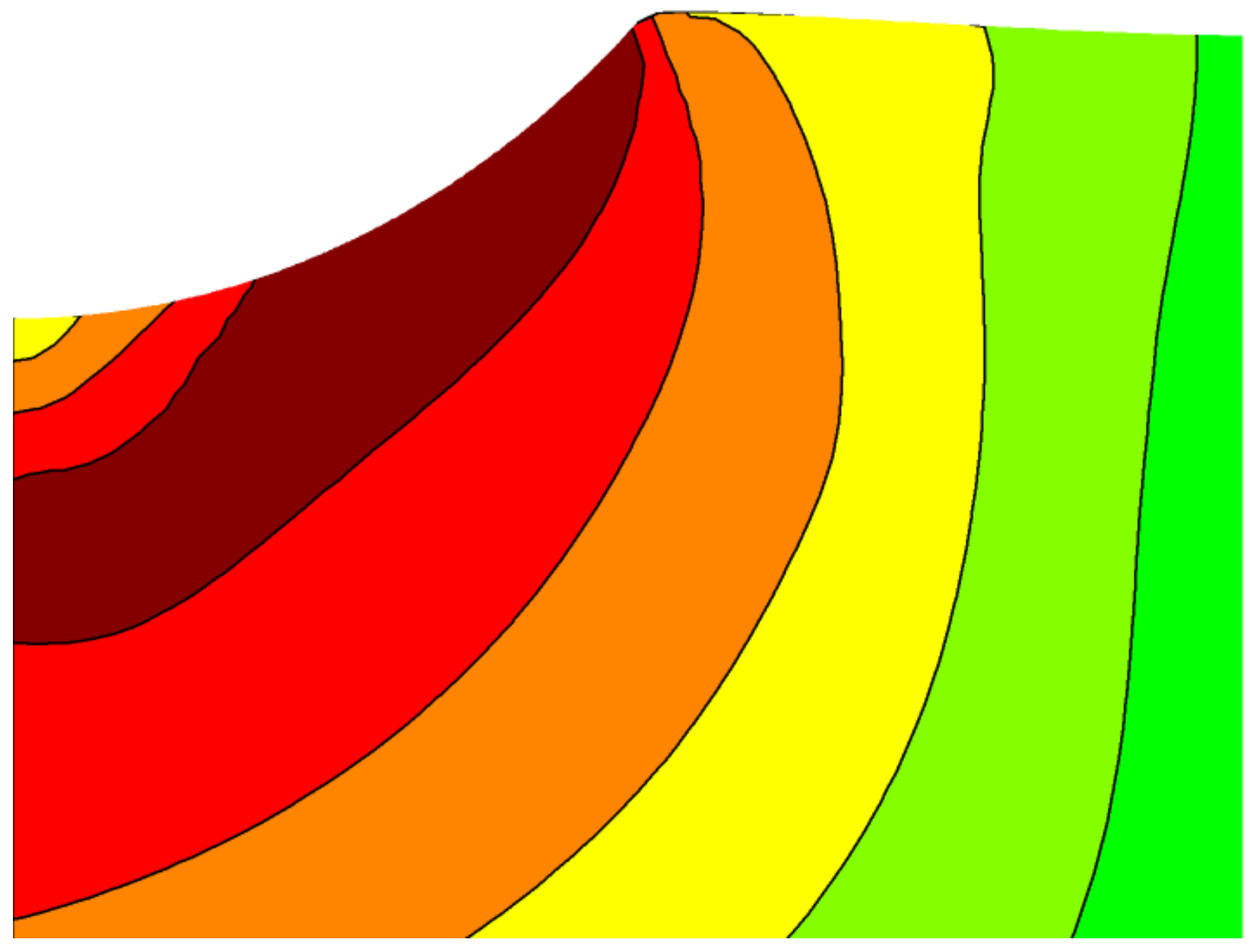

Mises/MPa

(Avg:75\%)

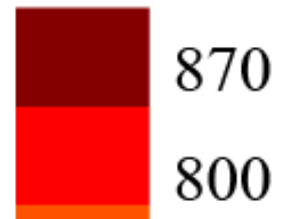

730

660

590

520

450

380

310

240

Figure 16

Mises stress distribution around indentation 


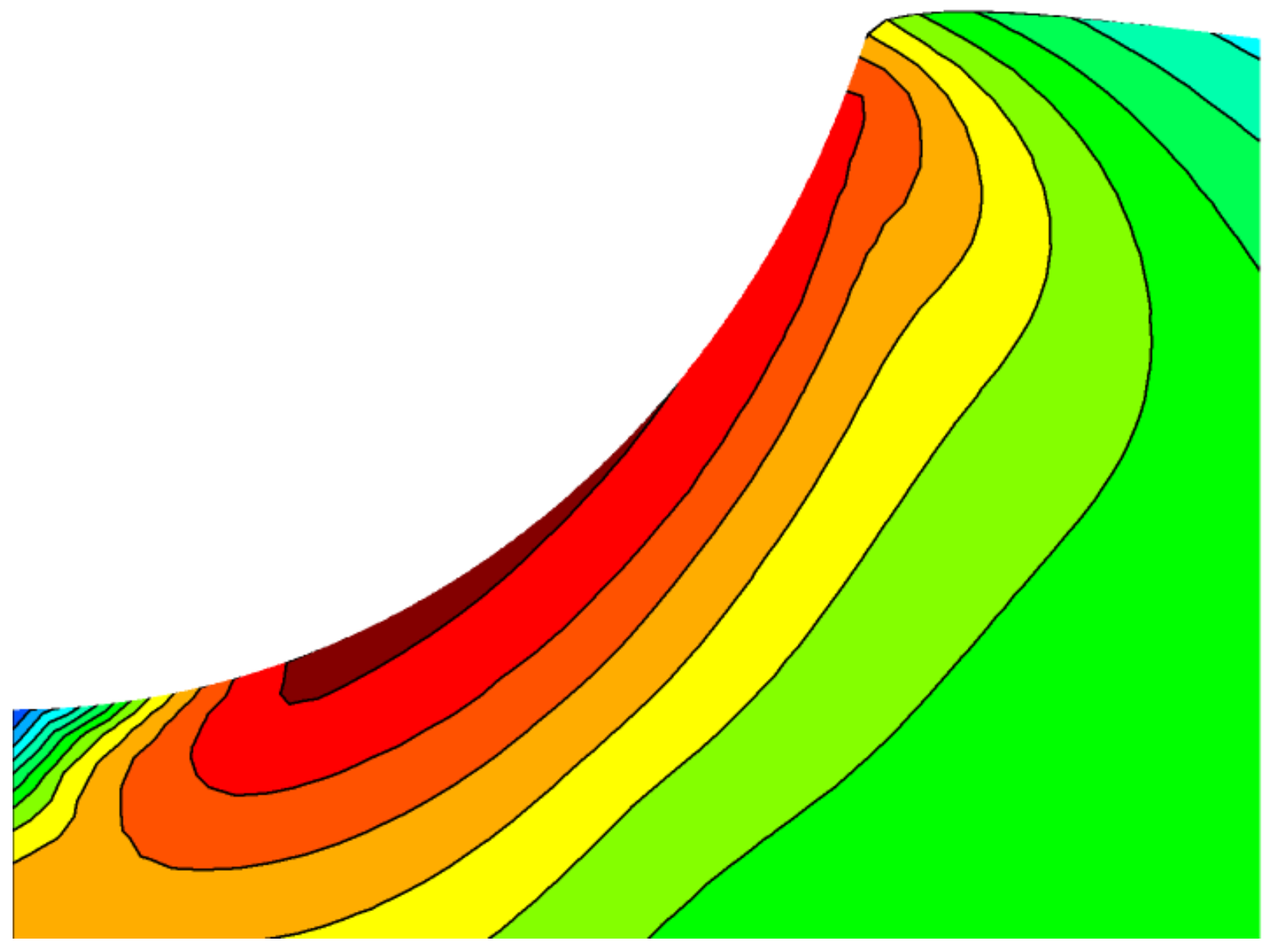

$\tau_{\max } / \mathrm{MPa}$

(Avg:75\%)

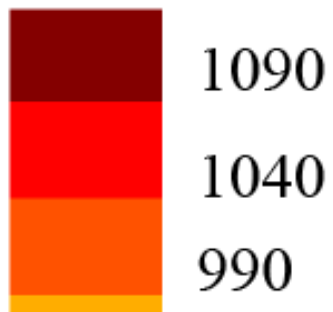

940

890

840

790

740

690

640

Figure 17

Shear stress distribution around indentation

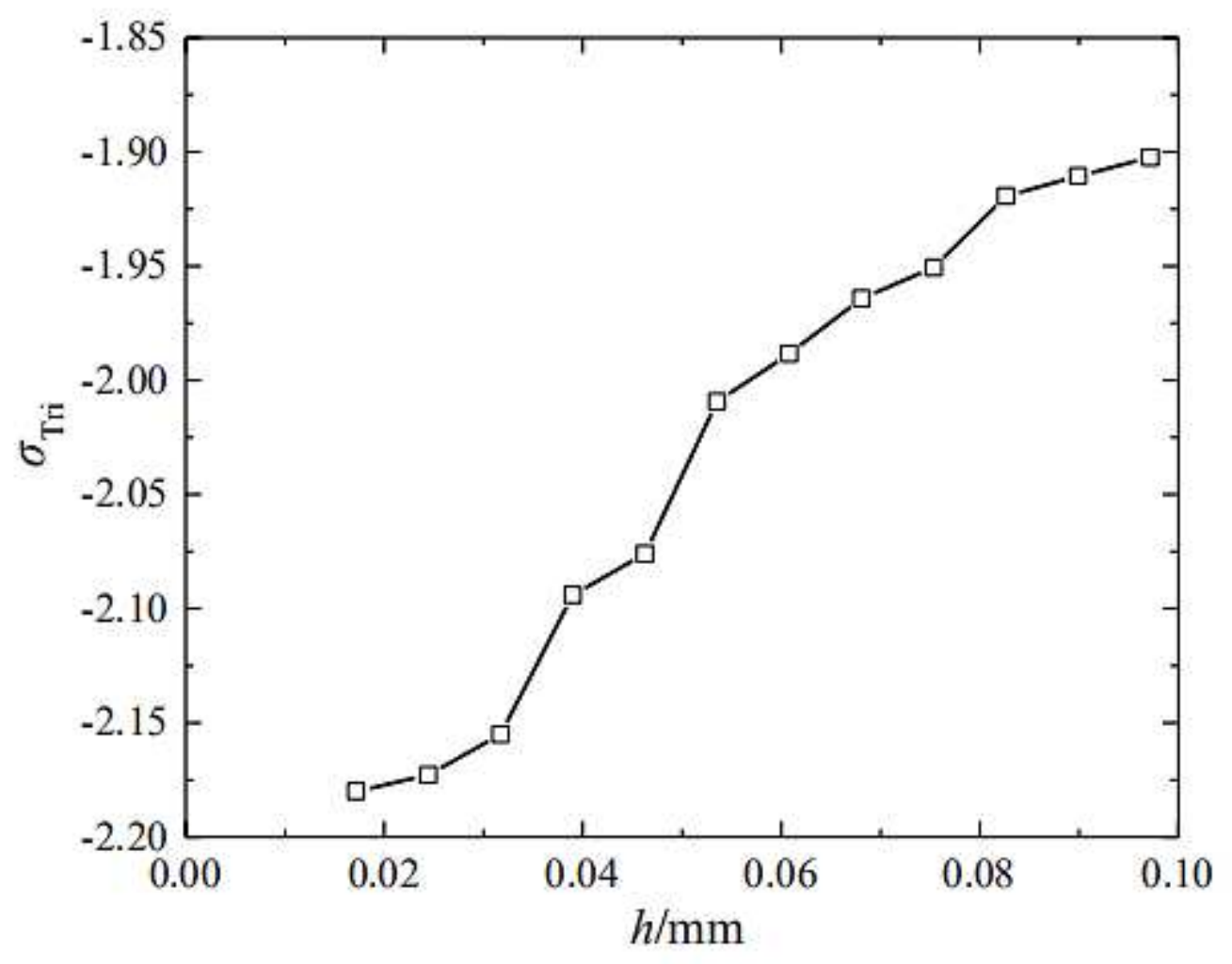


Figure 18

Variation of otri with q (the region of maximum shear stress)

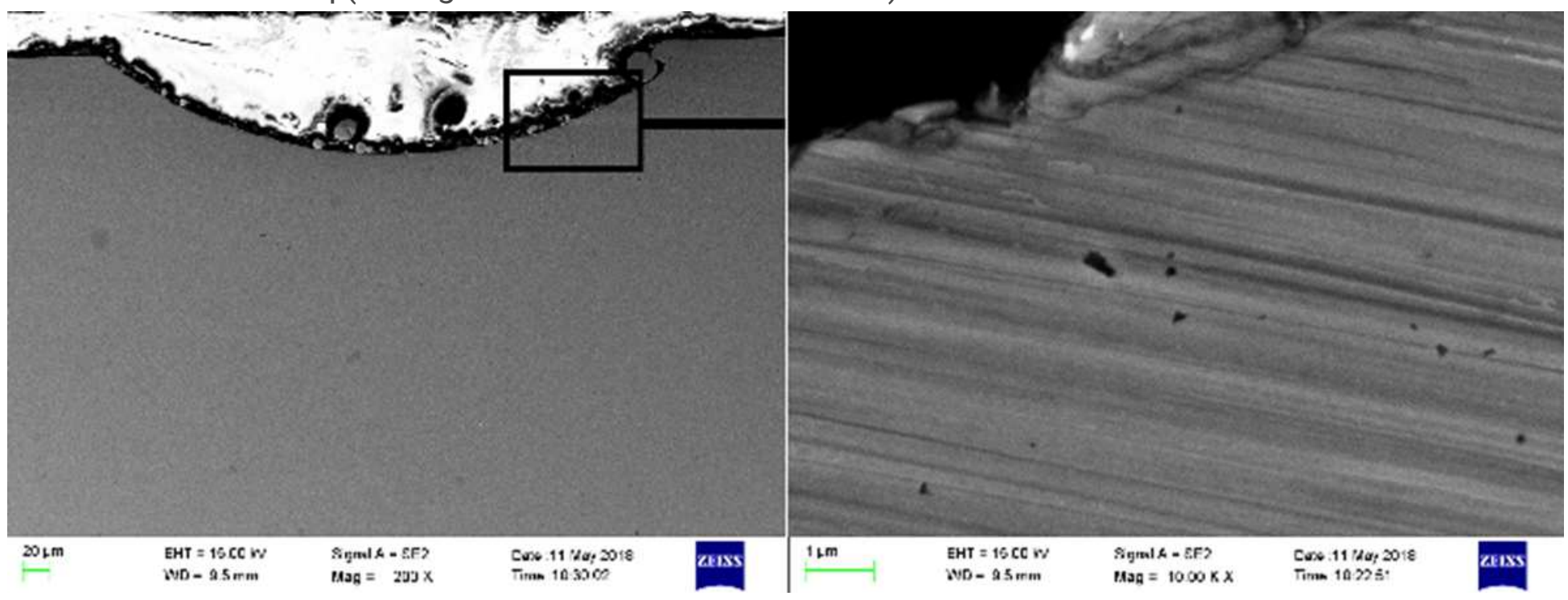

Figure 19

Microstructure of residual indentation

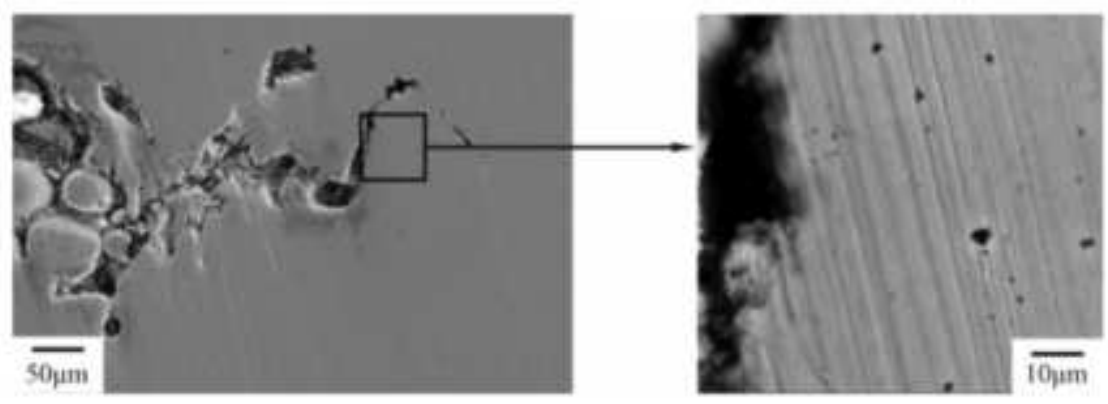

Figure 20

Observation of section surface for Mode I specimen [21] 


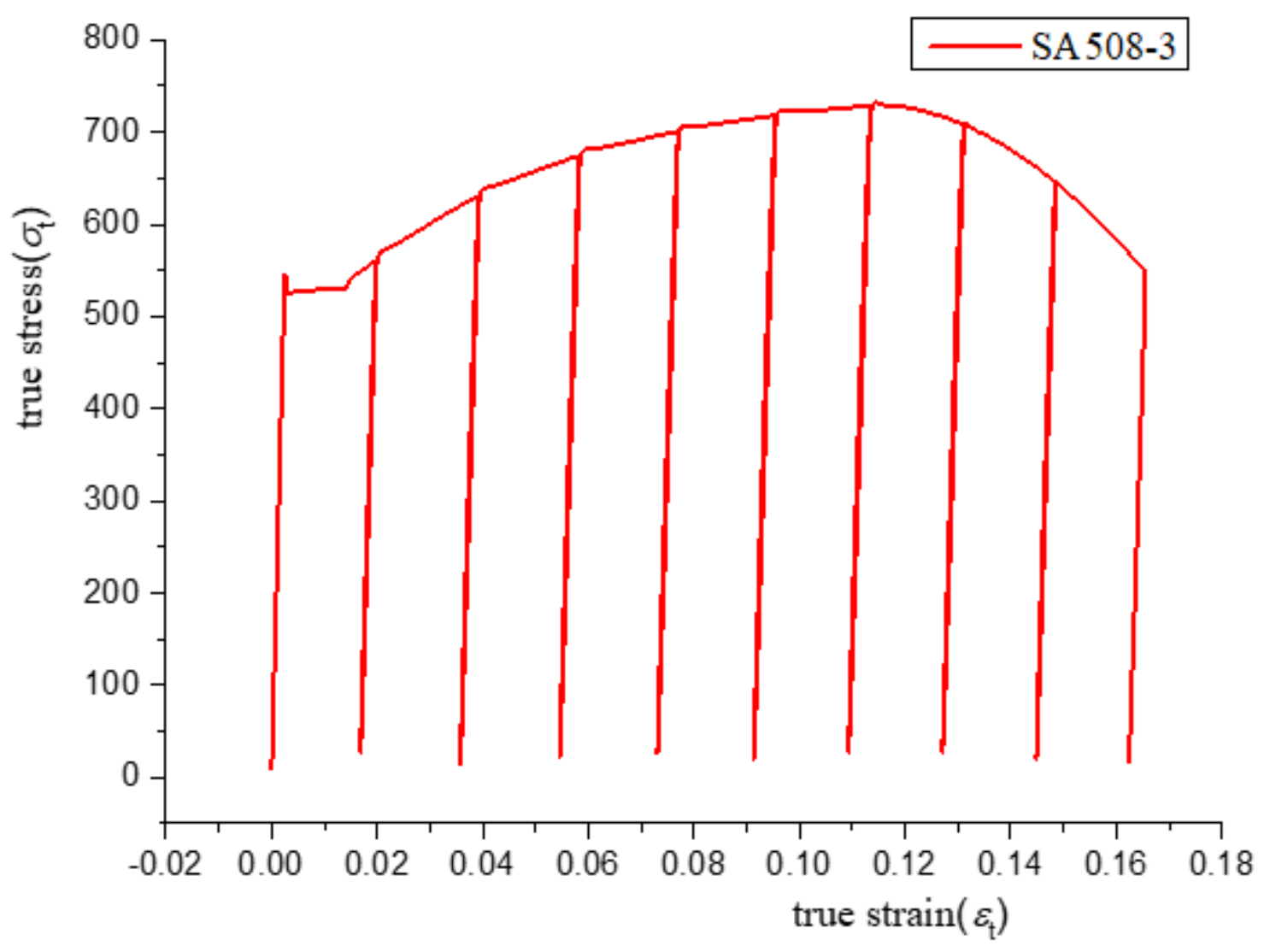

Figure 21

True stress-strain curve from cyclic loading tensile tests (SA508-3)

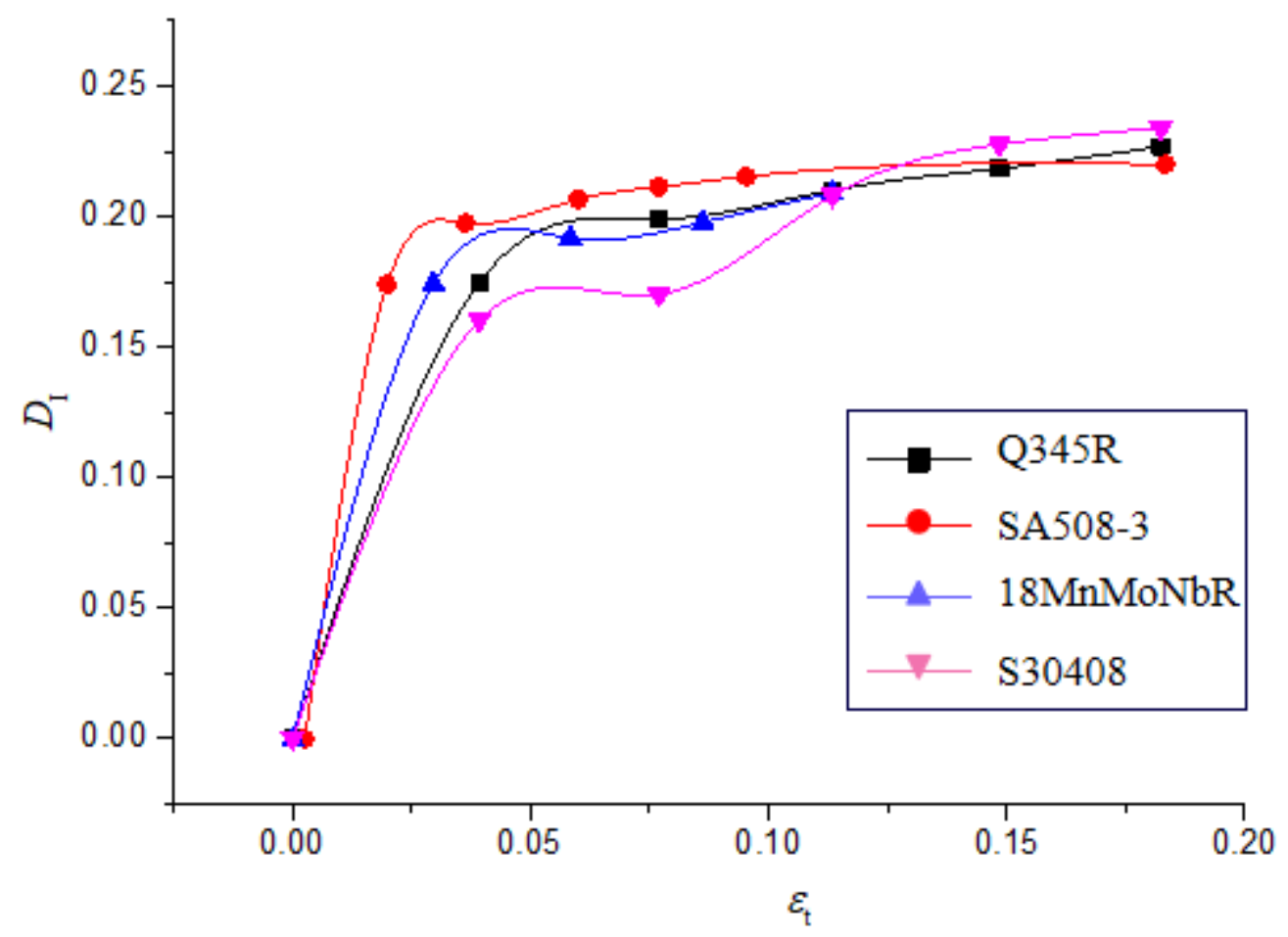


Figure 22

Variation of tensile damage with true strain

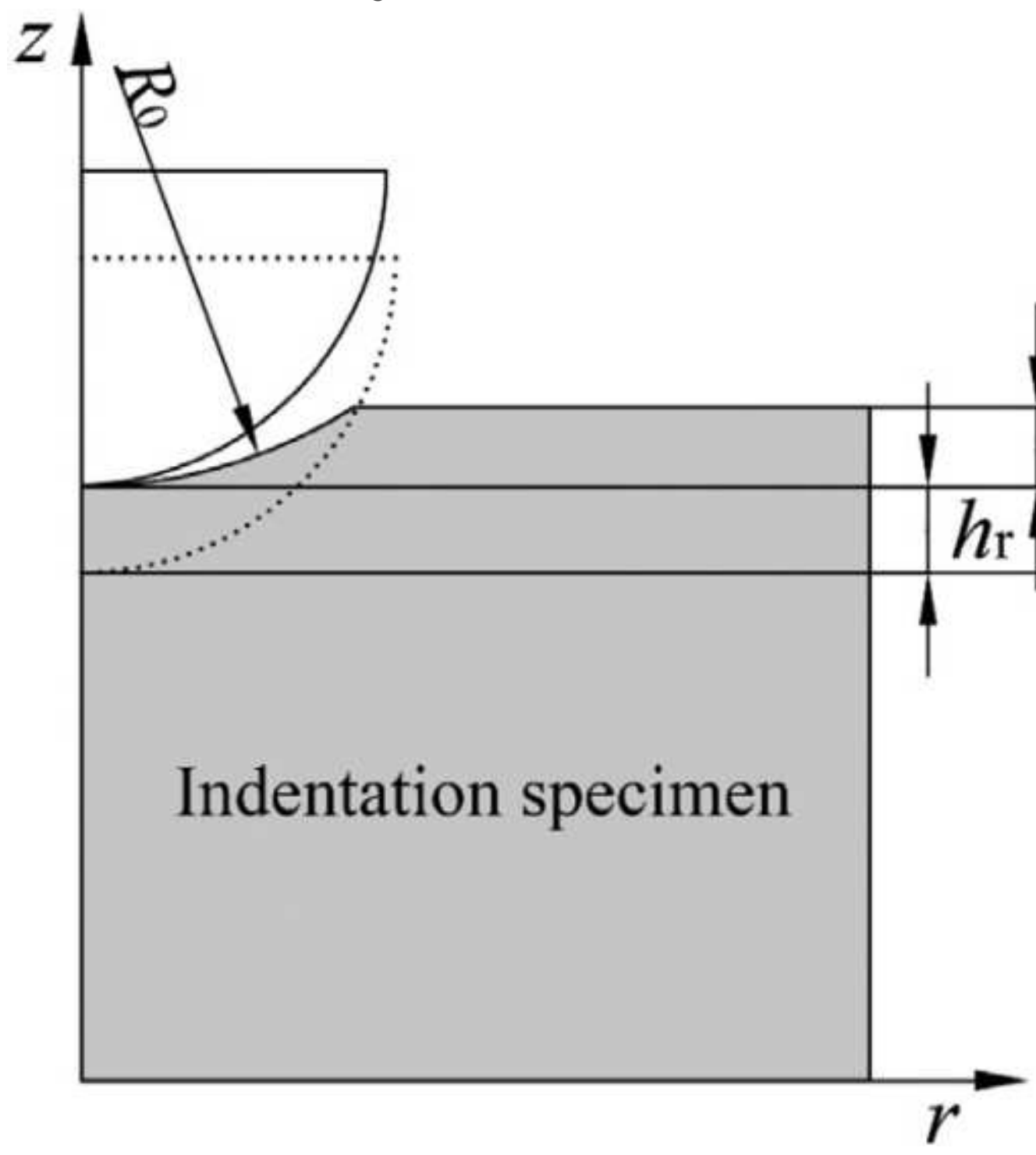

Figure 23

Illustration of the residual indentation surface [10]. 


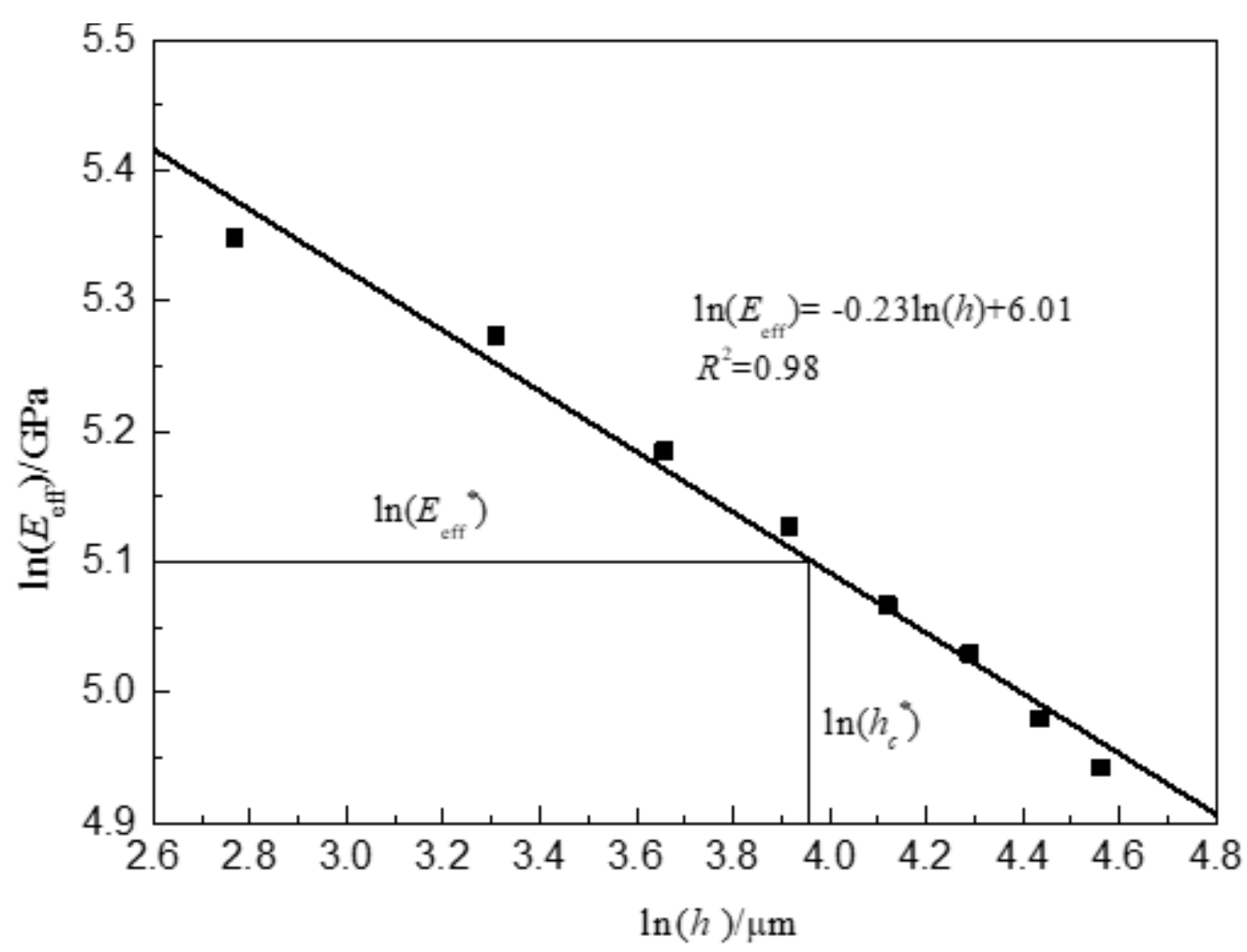

Figure 24

Linear correlation between InEeff and Inh (for SA508-3) 


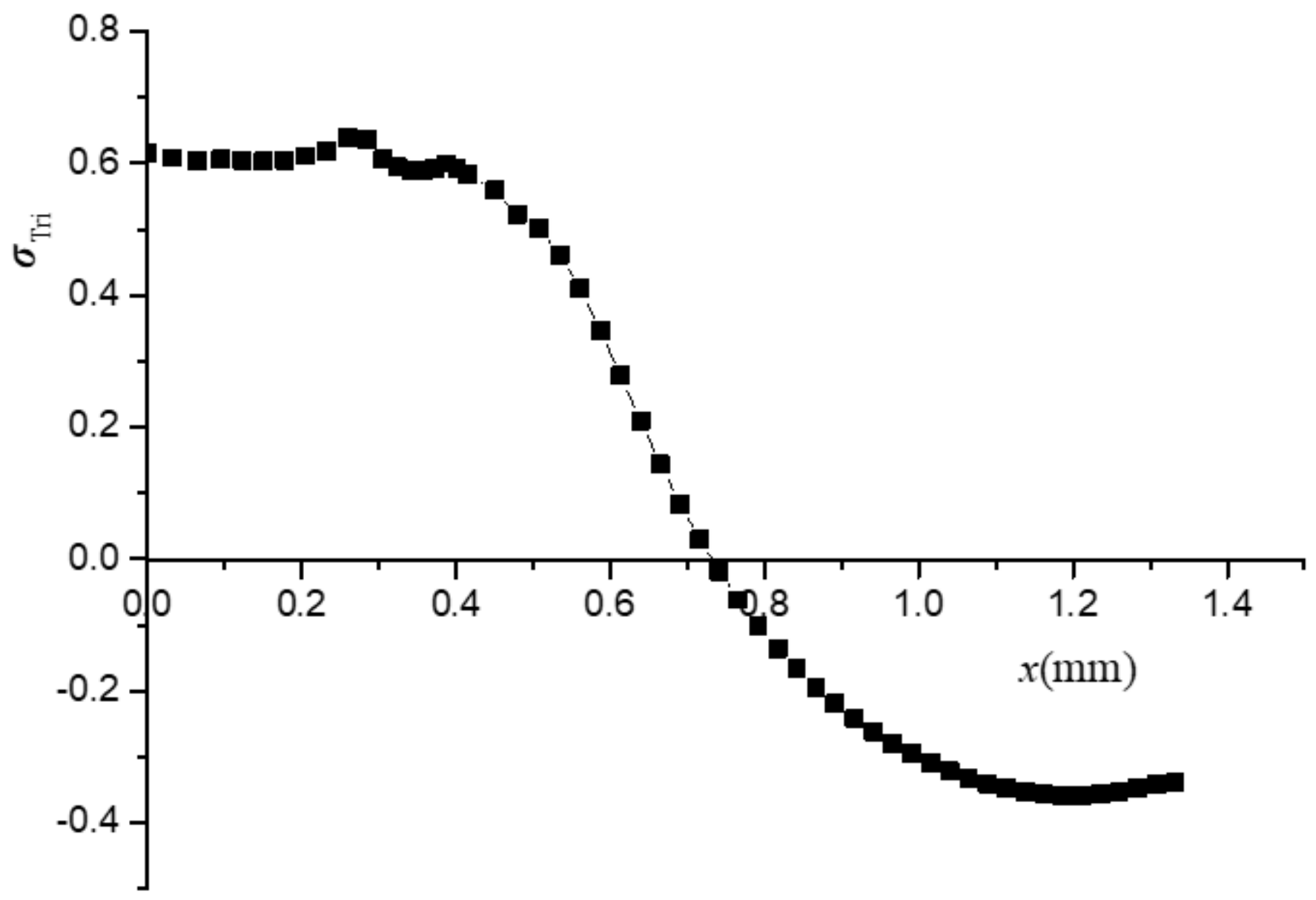

Figure 26

Stress triaxiality along the boundary of V-notch 


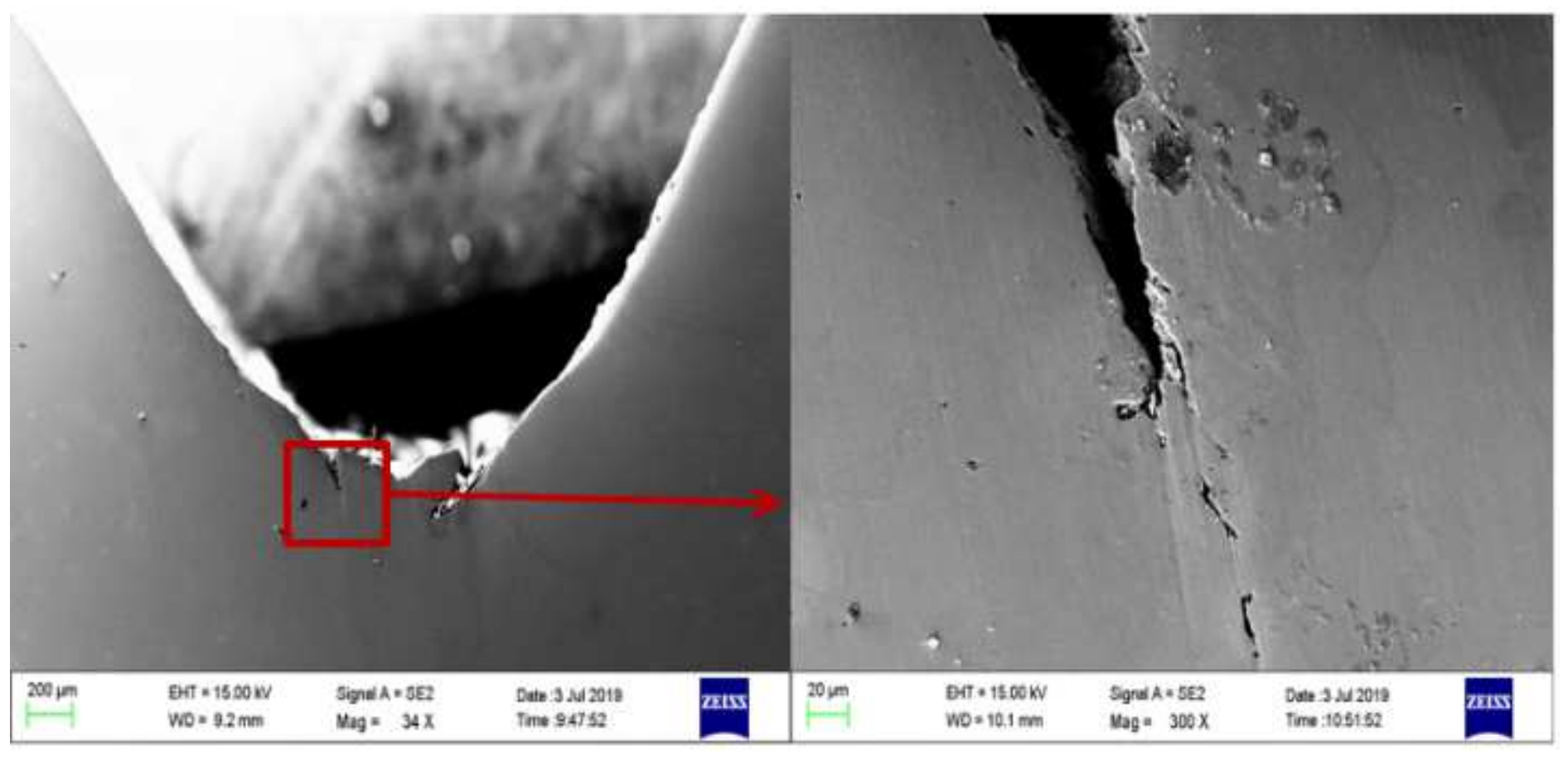

Figure 27

SEM observation of section surface for crack arrest specimen (Q345R) 


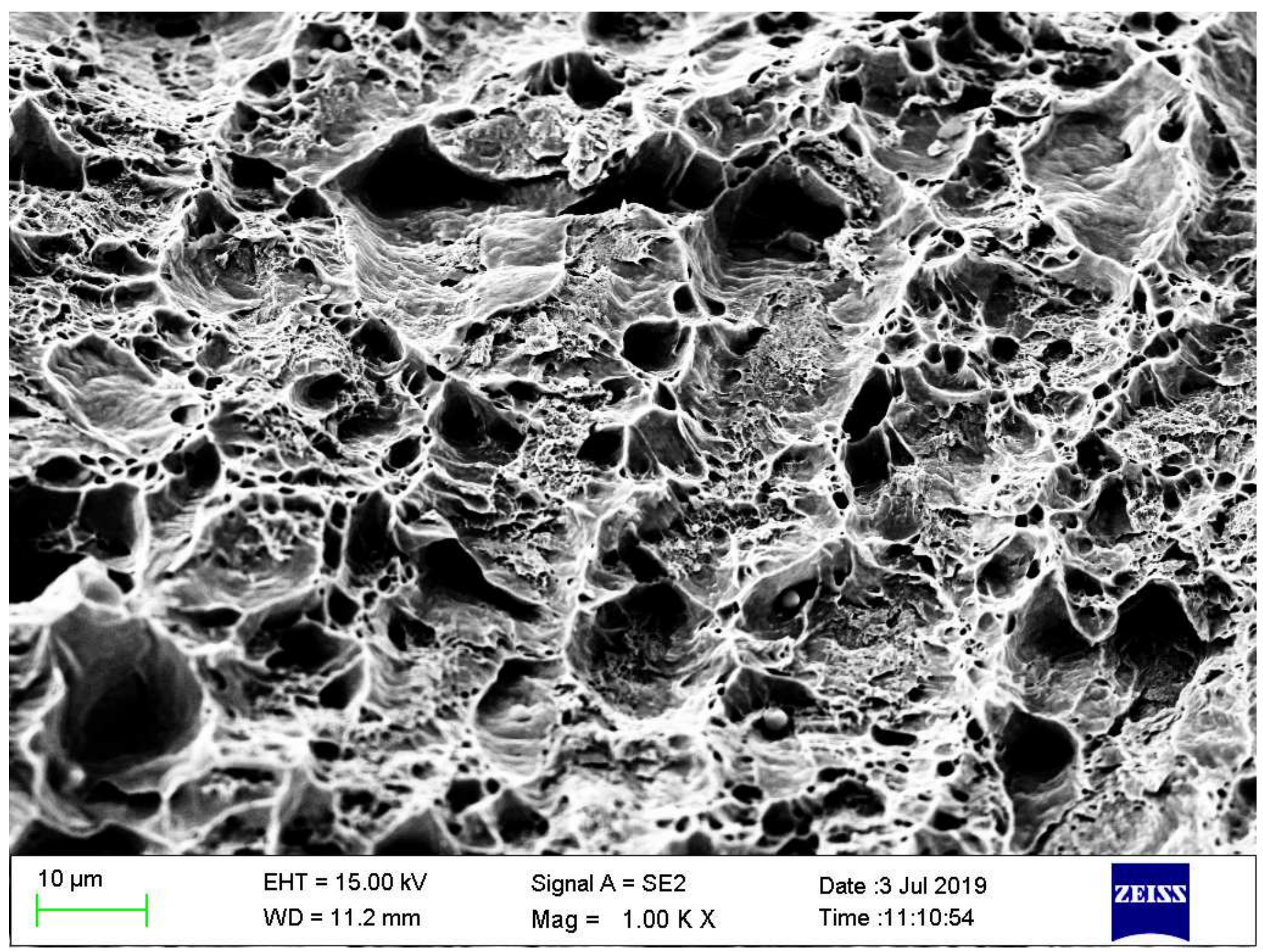

Figure 28

SEM observation of fracture surface for impact test specimen (Q345R) 


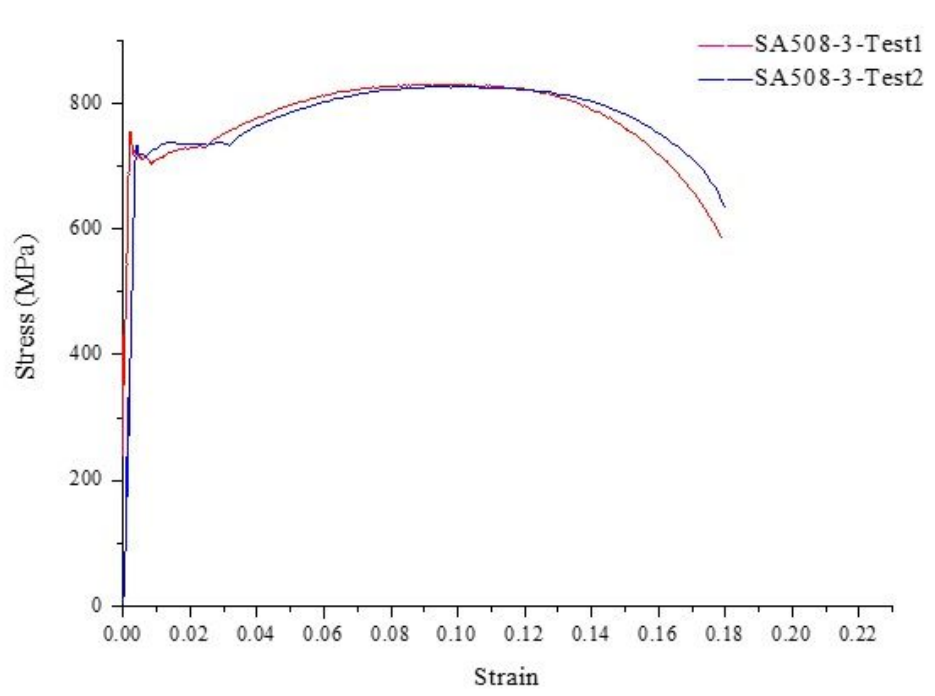

(a) SA508-3

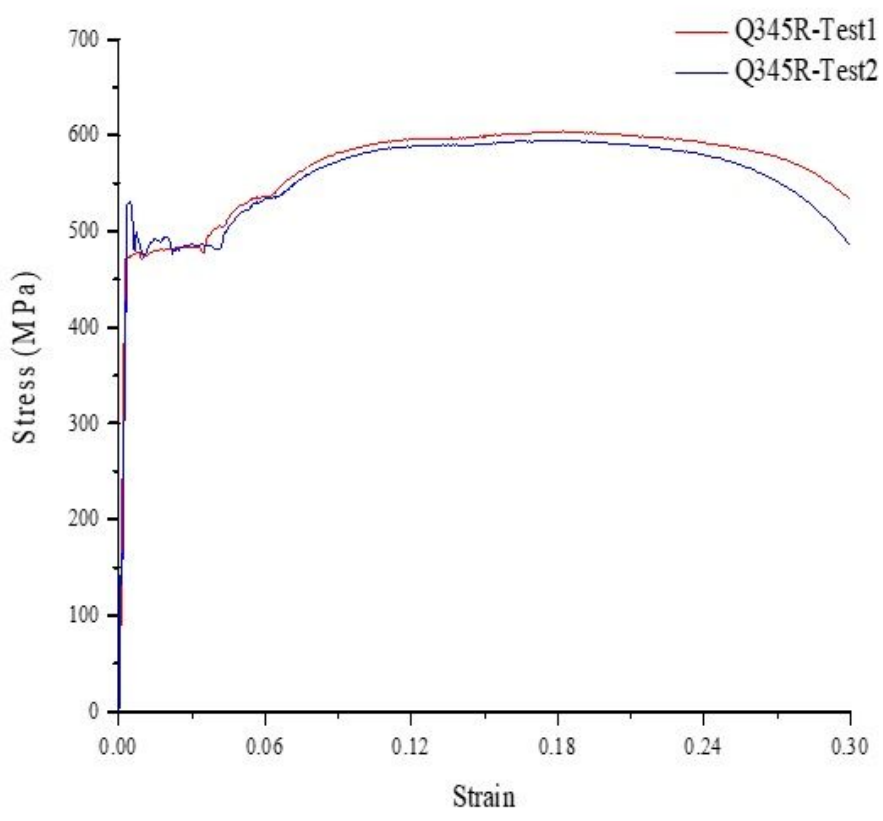

(c) Q345R

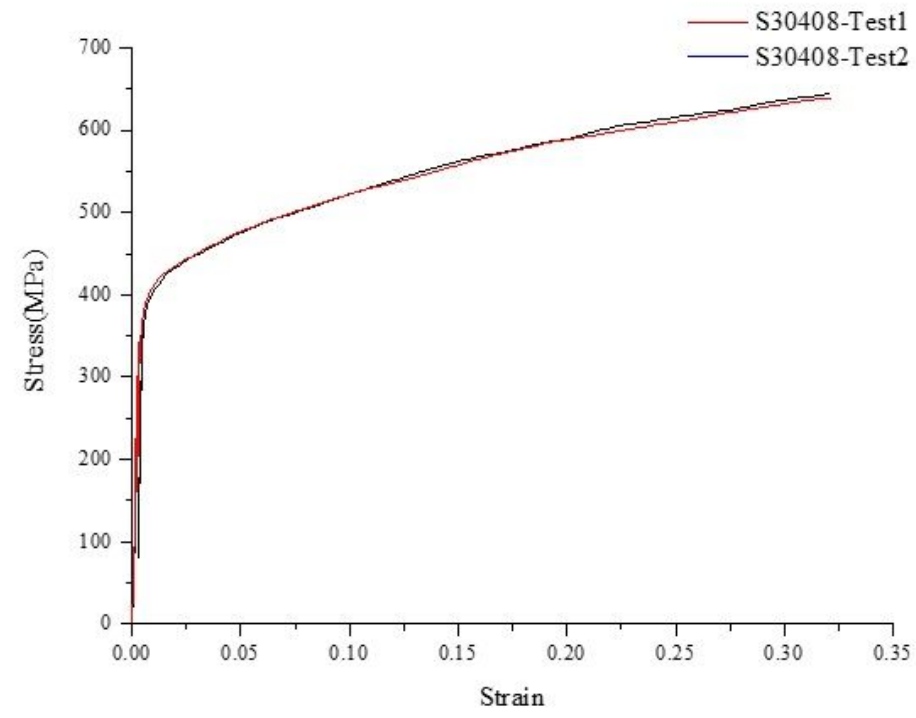

(b) $\mathrm{S} 30408$

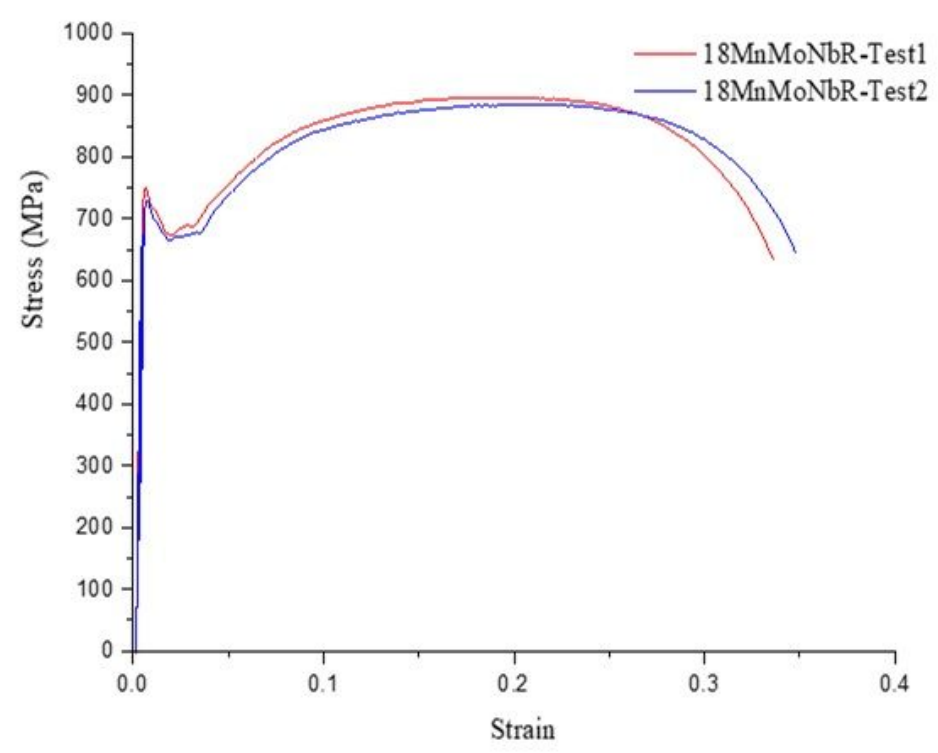

(d) $18 \mathrm{MnMoNbR}$

Figure 29

Stress-strain curve under dynamic tensile test 


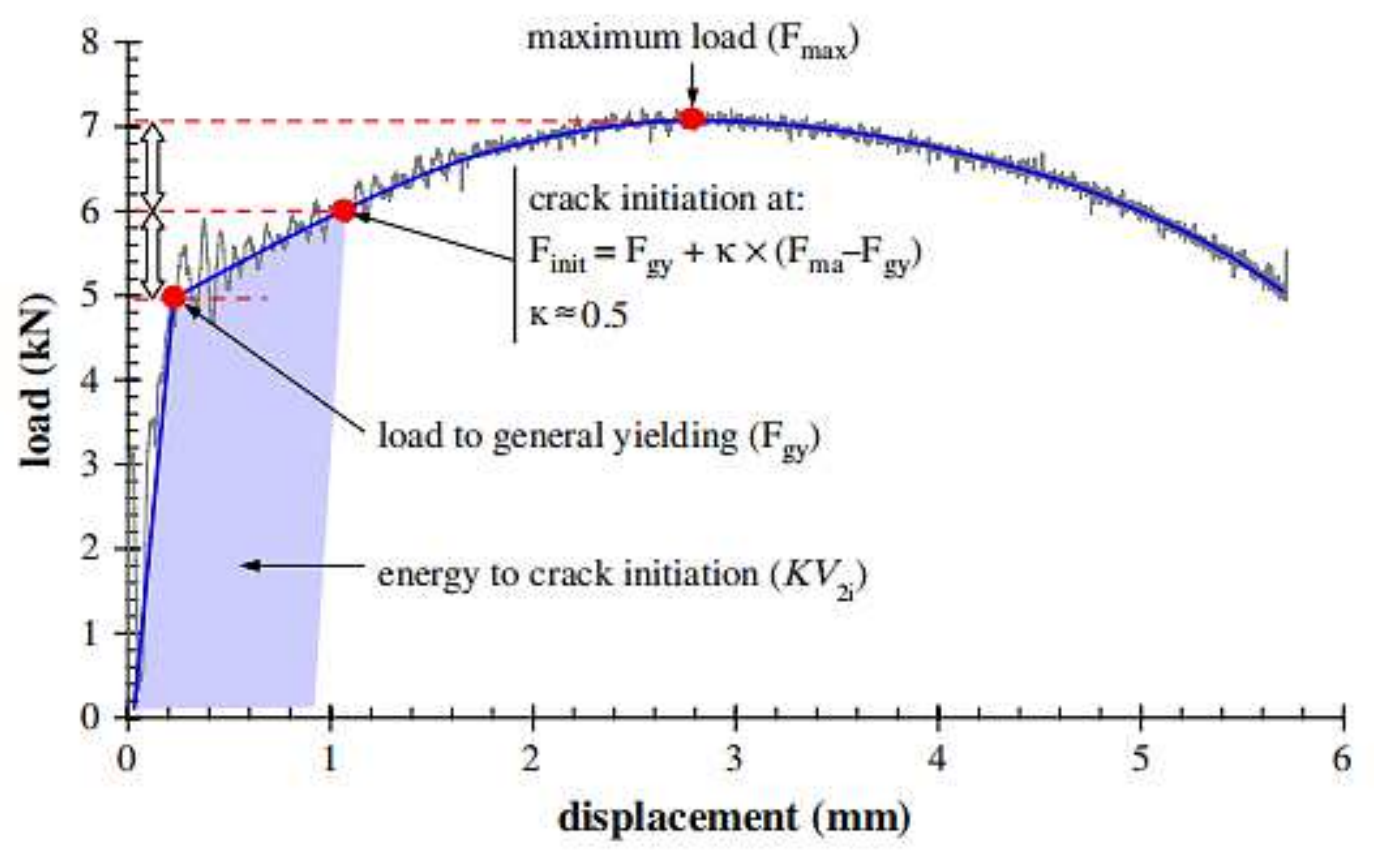

Figure 30

determined of crack initiation energy on the load-displacement curve [40] 


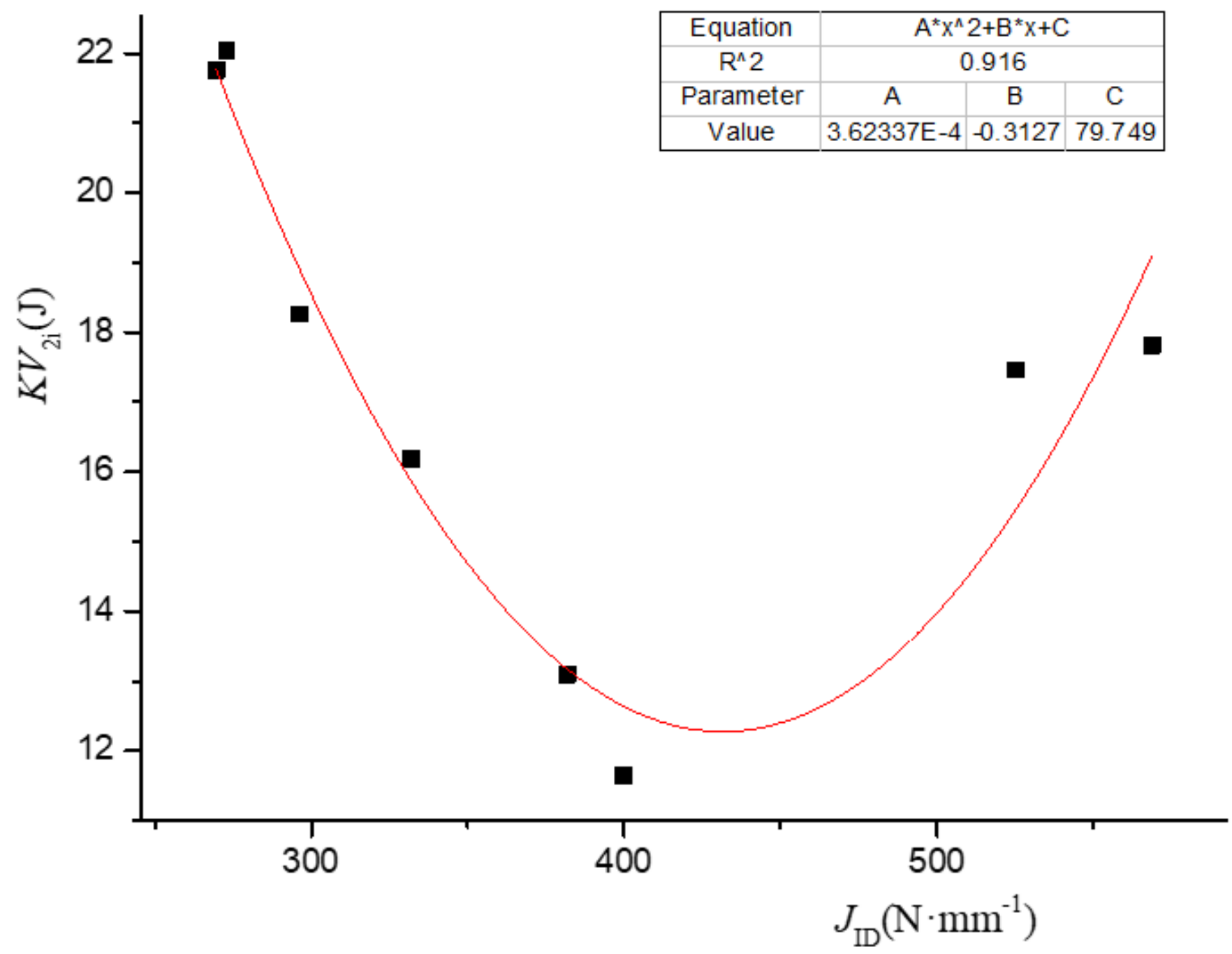

Figure 31

$\mathrm{KV} 2 \mathrm{i}$ - JID plot from tests and the fitting curve 


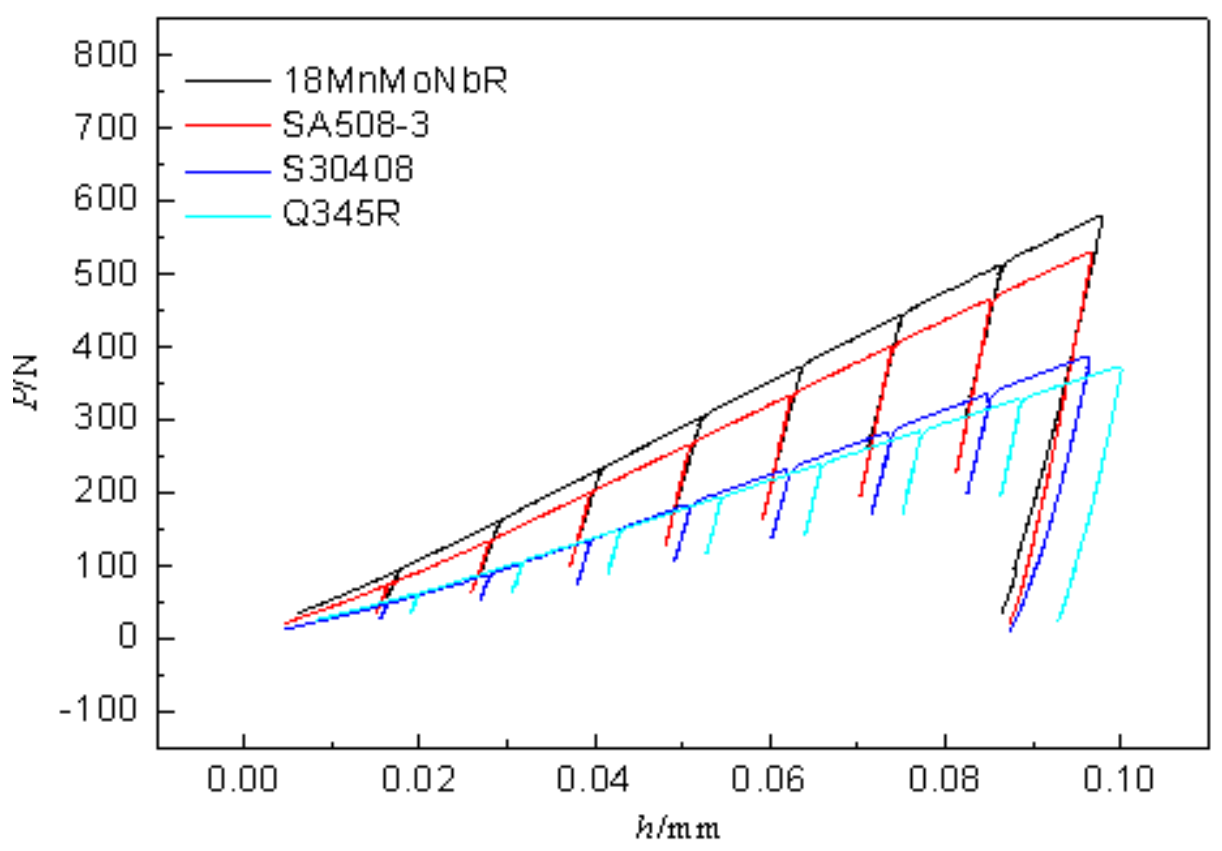

Figure 32

Load-displacement curve obtained from SITs 